\title{
The Puzzle of Index Option Returns
}

\author{
George M. Constantinides \\ University of Chicago and NBER
}

\author{
Jens Carsten Jackwerth \\ University of Konstanz
}

\author{
Alexi Savov \\ New York University
}

\begin{abstract}
We construct a panel of S\&P 500 Index call and put option portfolios, daily adjusted to maintain targeted maturity, moneyness, and unit market beta, and test multi factor pricing models. The standard linear factor methodology is applicable because the monthly port folio returns have low skewness and are close to normal. We hypothesize that any one of crisis related factors incorporating price jumps, volatility jumps, and liquidity (along with the market) explains the cross sectional variation in returns. Our hypothesis is not rejected, even when the factor premia are constrained to equal the corresponding premia in the cross section of equities. The alphas of short maturity out of the money puts become economically and statistically insignificant. (JEL G11, G13, G14)
\end{abstract}

The returns of index options are highly volatile, skewed, and non-linear in the index return, thereby rendering tests of linear factor pricing models hard to interpret. For example, over the period 1986-2012, a test of a linear factor model with the S\&P 500 Index as the sole factor on the cross-section of dailyrebalanced index option portfolio returns consisting of calls and puts of various maturities and moneyness yields an incredible monthly root mean squared (rms) error of $12 \%$. Yet the $p$-value is $32 \%-34 \%$ and the model is not rejected.

An important methodological contribution of this paper is the construction of a panel of leverage-adjusted (that is, with a targeted market beta of one) monthly returns of 54 option portfolios split across type (27 call and 27 put portfolios), each with targeted time to maturity (30,60, or 90 days), and targeted moneyness $(0.90,0.925,0.95,0.975,1.00,1.025,1.05,1.075$, or

\footnotetext{
We thank Muzaffer Akat, Michal Czerwonko, Günter Franke, Ben Golez, Bruce Grundy, Christopher Jones, Ralph Koijen, Stefan Ruenzi, Amir Yaron (the editor), an anonymous referee, and seminar participants at several universities for valuable comments. Constantinides acknowledges financial support from the Center for Research in Security Prices of the University of Chicago, Booth School of Business. Supplementary data can be found on the Review of Asset Pricing Studies Web site. Send correspondence to George Constantinides, Booth School of Business, University of Chicago, 5807 South Woodlawn Avenue, Chicago, IL 60637; telephone: (773) 702-7258; fax: (773) 753-8045. E-mail: gme@ChicagoBooth.edu.
}

(C) The Author 2013. Published by Oxford University Press on behalf of The Society for Financial Studies. All rights reserved. For Permissions, please email: journals.permissions@oup.com doi:10.1093/rapstu/rat004 
1.10). Each portfolio's weights are adjusted daily to maintain its targeted beta, maturity, and moneyness. The major advantage of this construction is to lower the variance and skewness of the monthly portfolio returns and render the returns close to normal (about as close to normal as the index return), thereby making applicable the standard linear factor pricing methodology. Using our portfolios, we strongly reject a model with the S\&P 500 Index as the sole priced factor. For the first time, we can now test pricing models with factor premia estimated either from the universe of stocks (the 25 Fama-French portfolios) or the universe of the 54 option portfolios and contrast the results.

We find that either one of two crisis-related factors (along with the market) reasonably explains the cross-section of call and put portfolio returns, reducing the monthly rms error from $44-47$ bps under the capital asset pricing model (CAPM) to about 20-24 bps when the factor premia are estimated from the universe of equities ( 13 bps using premia estimated from the universe of options). These are Jump, a factor that captures jumps in the price of the market index, and Volatility Jump, a factor that captures jumps in market volatility. Figures 1 and 2 display the time series of Jump and Volatility Jump, respectively, and Table 1 displays their correlation. The series are highly correlated $(-74 \%)$ and both capture major financial crises, including the October 1987 crash, the Asian financial crisis, the Russian default, 9/11, the WorldCom bankruptcy, and the Lehman bankruptcy. Furthermore, Jump and Volatility Jump reduce the pricing errors of the 25 Fama-French

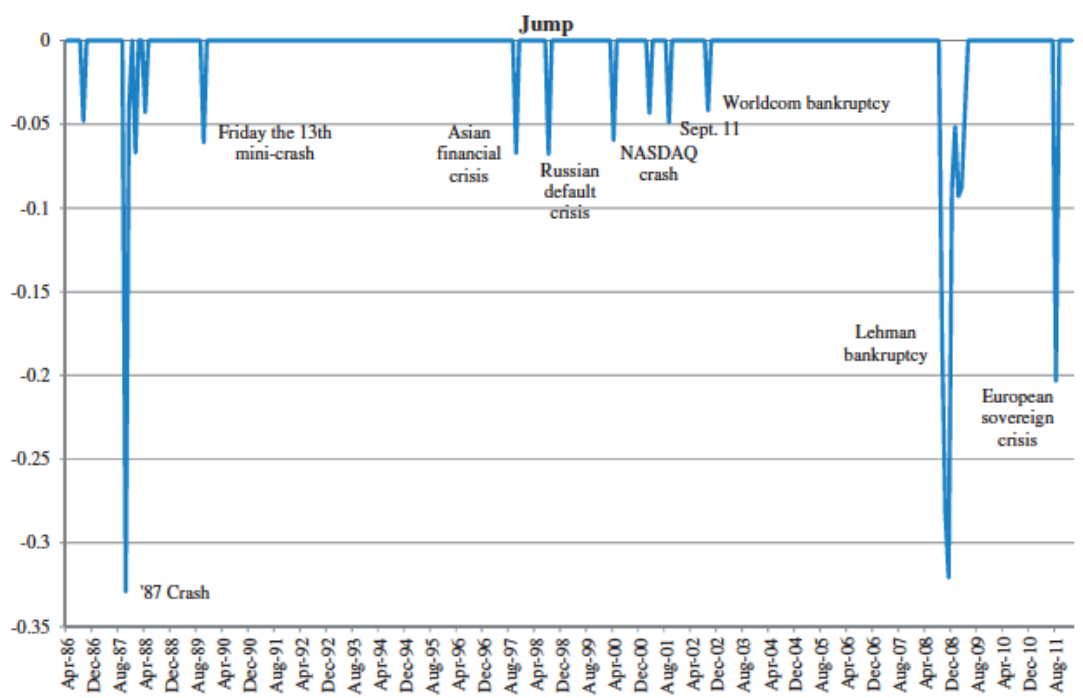

Figure 1

Time series of the Jump factor, April 1986 to January 2012. 


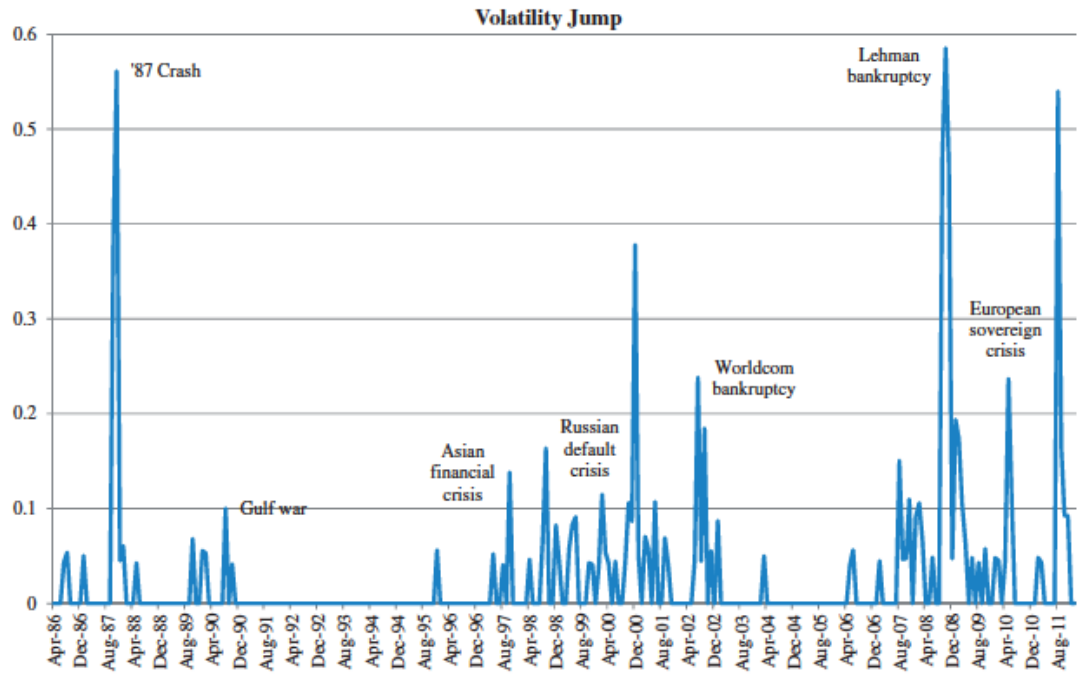

Figure 2

Time series of the Volatility Jump factor, April 1986 to January 2012.

Table 1

Pairwise correlations of our principal factors, April 1986 to January 2012

\begin{tabular}{lcccc} 
& Jump & Volatility Jump & Volatility & Liquidity \\
\hline S\&P & 0.43 & 0.44 & 0.60 & 0.29 \\
Jump & & 0.74 & 0.39 & 0.31 \\
Volatility Jump & & 0.28 & 0.28 \\
Volatility & & & 0.30 \\
\hline
\end{tabular}

S\&P is the excess return on the S\&P 500 Index. Jump is the sum of all daily S\&P 500 returns lower than $4 \%$ in a given month, zero if there are none. Volatility Jump is the sum of all daily increases in the ATM call portfolio implied volatility that are greater than $4 \%$, zero otherwise. Volatility is the ATM call portfolio implied volatility at the end of the month minus its value at the beginning of the month. Liquidity is the innovation in market-wide liquidity proposed by Pastor and Stambaugh (2003).

portfolios by more than size or momentum and almost as much as value. These two factors capture much of the spirit of stochastic volatility and stochastic jump models (e.g., Bates 1996; Eraker, Johannes, and Polson 2003).

Empirically, Volatility Jump performs better than Volatility itself since Volatility, as a factor, has rms error of 29 bps (13 bps using option based premia). Volatility is defined as the change in the implied volatility of our atthe-money index call portfolio. Volatility is plotted in Figure 3. Volatility is moderately correlated with Jump (-39\%) and Volatility Jump (28\%). It reaches peak values during the 1987 crash, the Russian default crisis, and the Lehman bankruptcy, among others.

A fourth factor that works almost as well in explaining the cross-section of index option returns is the Pastor and Stambaugh (2003) Liquidity factor. The rms error is 28 bps ( 13 bps using option based premia). Figure 4 displays the 


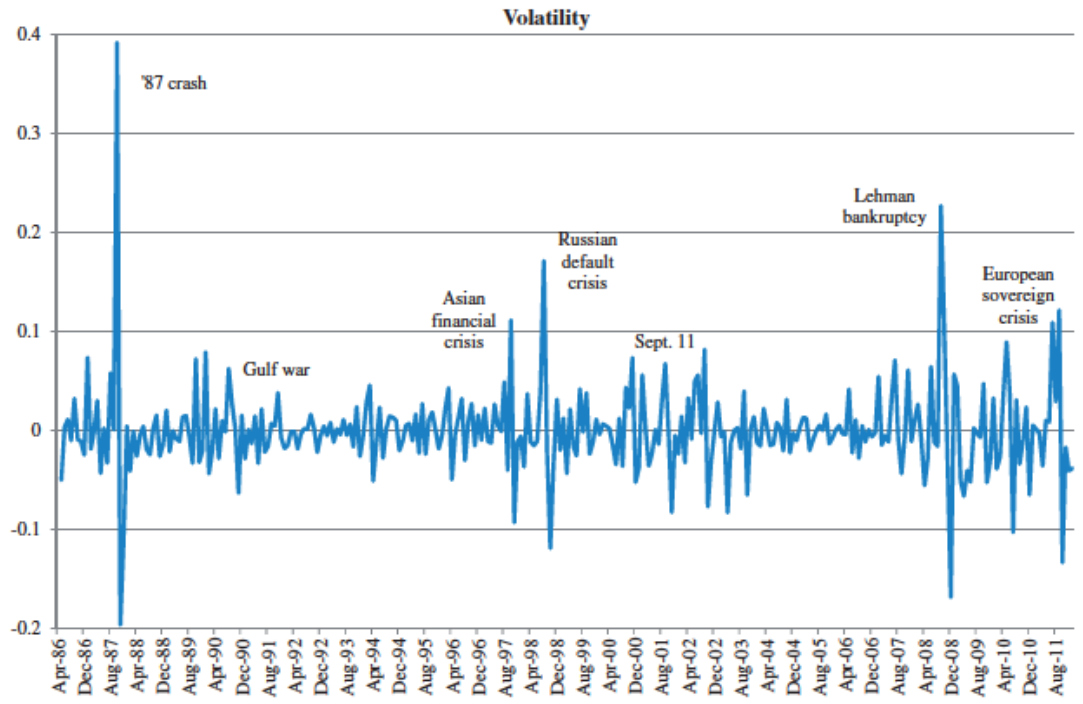

Figure 3

Time series of the Volatifity factor, April 1986 to January 2012.

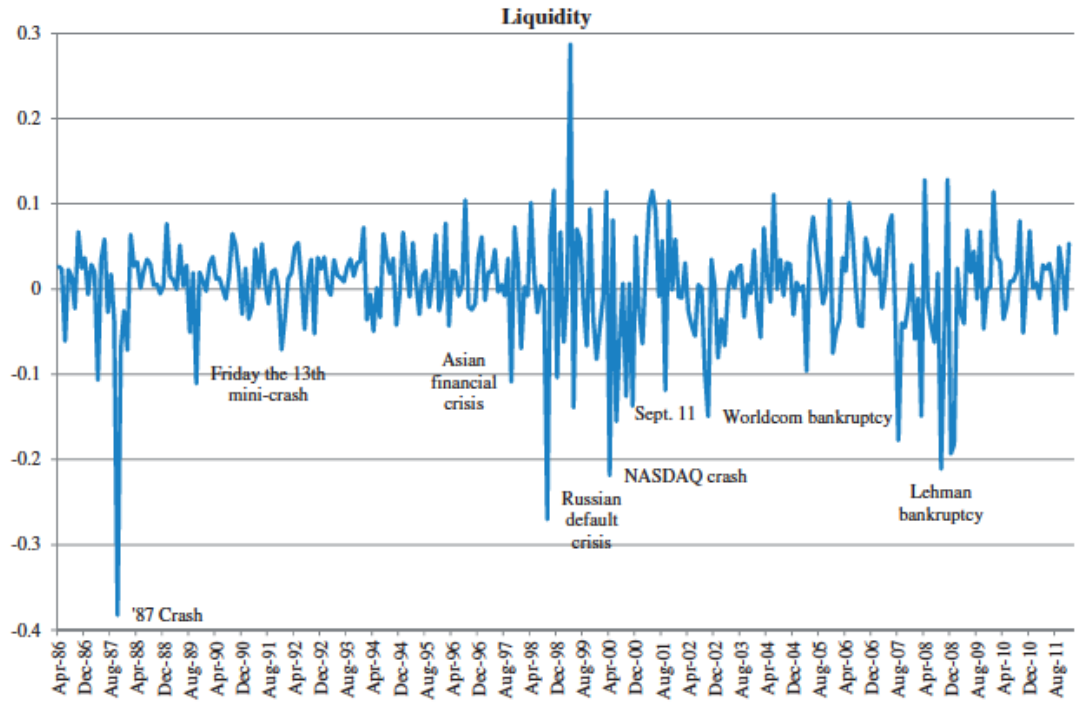

Figure 4

Time series of the Liquidity factor, April 1986 to January 2012.

time series of Liquidity. Liquidity is moderately correlated with Jump (31\%) and Volatility Jump ( $-28 \%)$ because, in addition to the above major financial crises, it captures other periods of changes in liquidity. Furthermore, Liquidity and Volatility are continuous measures whereas Jump and Volatility Jump are 
zero most of the time. A large number of additional factors entertained do not succeed in pricing the option returns.

Whereas we cannot reject the hypothesis that any one of crisis-related factors incorporating price jumps, volatility jumps, and liquidity (along with the market) explains the cross-sectional variation in returns, even when the factor premia are constrained to equal the corresponding premia in the cross-section of equities, about a quarter of the abnormal return to selling short-maturity out-of-the-money (OTM) puts remains unexplained. To address this remaining issue, we consider two extensions of the above twofactor unconditional pricing models. In the first extension, we add a third factor. With the combination of Volatility Jump and Liquidity as factors, none of the alphas is statistically significant even with equity-based factor premia. In the second extension, we consider a conditional factor model where the factor premia are affine in the lagged level of Liquidity. This extension reduces the overall pricing error by merely one basis point. However, the abnormal return of short-dated OTM puts falls to zero. We interpret this finding to suggest that OTM puts are particularly sensitive to market conditions.

Related research on factor models that address index option returns but without resorting to de-levering includes Jones (2006), Cao and Huang (2008), Carverhill, Cheuk, and Dyrting (2009), and Serban, Lehoczky, and Seppi (2008). Specifically, by not resorting to de-levering, the econometrics in Serban, Lehoczky, and Seppi (2008) turns out to be more complicated than for our linear factor models.

Unlike the earlier portfolio construction in Buraschi and Jackwerth (2001), we leverage-adjust the portfolios on a daily basis to maintain the targeted beta of one and gross up the daily returns to obtain monthly returns. This treatment has the effect of decreasing the volatility and skewness of returns and rendering them about as close to normal as the index itself. We do not pool calls and puts in the same portfolios and, as we show, put returns provide a different set of challenges to the pricing models than call returns do. Finally, unlike Buraschi and Jackwerth (2001), we test a wide range of factors, some of them novel, and identify a set of crisis-related factors as the ones that explain the cross-section of option returns.

The closest related studies to our work are two studies that look at index option returns and, at least initially, de-lever the positions but then do not keep on adjusting the positions. Coval and Shumway (2001) rejected the onefactor market model for the index option returns by showing that zero-beta at-the-money (ATM) straddles produce negative returns. Broadie, Chernov, and Johannes (2009) used similar straddles plus spreads and suggested that a jump factor helps explain the option portfolio returns. Constantinides, Jackwerth, and Perrakis (2009) and Constantinides et al. (2011) also rejected the one-factor market model by showing that option portfolio strategies stochastically dominate the market portfolio. 
Our second connection to the literature is via the numerous suggested priced factors that may influence option returns over and above the market. Many of these models are critically discussed in Jackwerth (2004), Singleton (2006), Lian (2011), Hull (2012), and McDonald (2013). Individual factors have been suggested by Rietz (1988), Bollen and Whaley (2004), Barro (2006), Christoffersen, Heston, and Jacobs (2006), Bates (2008), Brennan, Liu, and Xia (2008), Buraschi, Trojani, and Vedolin (2011), and Drechsler and Yaron (2011). None of these papers allows for the linear factor model specification of options returns as we present it in our paper. For related research on suggesting factors for individual stock options, see Duarte and Jones (2007), Buraschi, Trojani, and Vedolin (2011), and Christoffersen et al. (2011).

The paper is organized as follows. In Section 1, we describe the data sets, filters, and the formation of option portfolios. We present our empirical results on crisis-related factors in Section 2. In Section 3, we consider two extensions, three-factor unconditional pricing models, and conditional factor models. We conclude in Section 4. In the Appendices, we present robustness tests and technical material. Additional results are contained in the Online Appendix.

\section{Data Sets, Filters, and Portfolio Formation}

A cross-section of index option returns of different moneyness and maturities presents a novel set of technical challenges. The first one is to obtain statistically significant variation in the cross-section of returns because estimation errors, which could be driven in part by data errors, may lead to the conclusion that even naïve models are consistent with the data - a point made by Broadie, Chernov, and Johannes (2009). We address this issue by constructing a cross-section of portfolios of options with different moneyness and maturity as opposed to individual options. We construct the return series of 54 portfolios of S\&P 500 European-style options (SPX). Each portfolio is made up of either calls or puts with one of nine target moneyness ratios: $K / S$ $=0.90,0.925,0.95,0.975,1.00,1.025,1.05,1.075$, and 1.10; and one of three target maturities: 30, 60, or 90 days. Our data starts in April 1986 and ends in January 2012. We carry out our main tests over this time period. We verify the robustness of our results by also analyzing the subsample that excludes the destabilizing effects of the 1987 crash and the 2007-2009 financial crisis.

The second challenge is to generate portfolio returns that are stationary and only moderately skewed. We address this issue by deleveraging the portfolios to have a target market beta of one. In constructing a leverage-adjusted portfolio, we approximate the elasticity with respect to the index with the elasticity implied by the Black and Scholes (1973) and Merton (1973) (BSM) model, without, however, presuming that this elasticity equals the true elasticity with respect to the index: in our tests, we explicitly adjust for the market 
beta instead of asserting that it equals one. We also revise the portfolios daily in a way that the moneyness, maturity, and leverage of each portfolio remain fairly constant. The procedure significantly reduces the variability and skewness of returns and produces returns about as close to normal as the index itself. We validate our primary findings on monthly holding period returns with deleveraging but without daily rebalancing.

The third challenge stems from the occasional lack of price quotes when we wish to trade out of an options position, which may lead to survivorship bias, look-ahead bias, or the revision of the portfolios at artificial prices. We address these problems and also demonstrate that our results are insensitive to the method of portfolio revision.

\subsection{Data sets}

The master Berkeley Options Database contains intraday quotes on individual SPX options from April 2, 1986 through December 31, 1995. To be consistent with the OptionMetrics database, which reports only closing prices, we extract from the master Berkeley Options Database a sample of closing prices and refer to it as the "Berkeley database." We describe the construction of the Berkeley database in Appendix A.

The OptionMetrics database contains end-of-day quotes from January 4, 1996 to January 31, 2012. The end-of-day quotes are collected using a proprietary method similar to the one we outlined for the Berkeley database. OptionMetrics provides the dividend yield and open interest of each option contract, and we collect that as well.

The bid-ask spreads of calls and puts, as a percentage of the average bid and ask prices, are generally similar for the Berkeley and OptionMetrics data sets. The spreads for ATM and in-the-money (ITM) options are about 5\%. The percentage spreads for OTM options are typically two to three times higher.

\subsection{Filters}

We sift the option prices through several filters to ensure that only options with reliable quotes enter our portfolios. The filtered data consist of 173,125 observations from the Berkeley database (52\% calls) and 824,397 observations from OptionMetrics (49\% calls). The filters are described in Appendix B. In the Online Appendix, we demonstrate the robustness of our pricing results when we lift the filters.

\subsection{Portfolio formation}

We use the filtered data to form 54 portfolios, 27 made up of calls and 27 made up of puts, each with targeted time to maturity of 30,60 , or 90 days and targeted moneyness of $0.90,0.925,0.95,0.975,1.001 .025,1.05,1.075$, or 1.10 , where moneyness is the ratio of the strike price to the index price. 
For each portfolio, we use a bivariate Gaussian weighting kernel in moneyness and days to maturity to calculate the option weights. The weighting kernel has bandwidths of 10 days to maturity and 0.0125 in moneyness, although alternative settings make little difference. We remove from the portfolio options with portfolio weights lower than $1 \%$ to reduce the effect of outliers on our targeted portfolios. The weights are normalized to sum to one. We recalculate each portfolio's option weights and revise each portfolio daily.

We calculate the one-day arithmetic return of an option under the assumption that we buy and sell it at its bid-ask midpoint. One may argue that transaction costs derail our rebalancing, which is carried out at the bid-ask midpoints. Note that we motivate portfolio rebalancing as a statistical procedure for obtaining monthly portfolio returns with distribution close to normal rather than as an implementable trading strategy. As a robustness check, we validate our primary findings on monthly holding period returns without daily rebalancing and report the results in the Online Appendix.

We convert an option's one-day return to a leverage-adjusted return by calculating the one-day return of a hypothetical portfolio with $\omega_{B S M}^{1}$ dollars invested in the option and $1-\omega_{B S M}^{1}$ dollars in the risk-free rate, where $\omega_{B S M}$ is the BSM elasticity based on the implied volatility of the option. The BSM elasticity is $\left(\partial C_{B S M} / \partial S\right) \times\left(S / C_{B S M}\right)>1$ for a call and $\left(\partial P_{B S M} / \partial S\right) \times$ $\left(S / P_{B S M}\right)<-1$ for a put. A leverage-adjusted call option portfolio consists of a long position in a fraction of a call and some investment in the risk-free rate; a leverage-adjusted put portfolio consists of a short position in a fraction of a put and more than $100 \%$ investment in the risk-free rate. In the next step, we combine the leverage-adjusted option returns into portfolio returns using the weights obtained through the weighting kernel. Finally, we compound the daily portfolio returns into monthly returns.

If a held option has bid and ask quotes in the filtered data, we use the bidask midpoint as the trade-in or trade-out price; if it does not have bid and ask quotes in the filtered data but has quotes in the unfiltered data, we use the bidask midpoint of these quotes as the trade-out price. If not, we check if the option is about to expire. If it is, we use its expiration payoff as the trade-out price. If expiry is not imminent, we hold the option in the portfolio until it reappears, or until the end of the month, whichever comes first. If the option fails to reappear by the end of the month, we compute an interpolated price by fitting an implied volatility surface that is linear in maturity, quadratic in moneyness, and linear in the interaction of maturity and moneyness to the log-implied volatilities of the available filtered options and use the fittedimplied volatility to deduce a price for the missing option. When holding on to a missing option, we keep it on the books at the purchase price and rescale its weight, dividing it by the daily portfolio return to fix the original dollar investment in the option. When the option reappears, its new price 
Table 2

Summary statistics for the call and put portfolios, April 1986 to January 2012

Calls

Puts

\begin{tabular}{lrrrrrrrr}
\cline { 3 - 5 } \cline { 6 - 8 } Observations & \multicolumn{2}{c}{ Berkeley } & \multicolumn{2}{c}{ OptionMetrics } & & \multicolumn{2}{c}{ Berkeley } & OptionMetrics \\
\hline Found & 67,652 & $81 \%$ & 314,784 & $100 \%$ & 62,922 & $76 \%$ & 327,199 & $100 \%$ \\
Missing & 15,714 & $19 \%$ & 336 & $0 \%$ & 20,267 & $24 \%$ & 311 & $0 \%$ \\
Expired & 219 & $0 \%$ & 14 & $0 \%$ & 324 & $0 \%$ & 19 & $0 \%$ \\
\hline
\end{tabular}

Last trading day of the month

\begin{tabular}{lrrrrrrrr}
\hline Found & 3,655 & $81 \%$ & 15,550 & $100 \%$ & 3,438 & $76 \%$ & 15,856 & $100 \%$ \\
Interpolated & 876 & $19 \%$ & 42 & $0 \%$ & 1,094 & $24 \%$ & 34 & $0 \%$
\end{tabular}

Filters are applied on the buy side but relaxed on the sell side. Found observations are those options with records on the day following the purchase day. (If the same option is bought and sold two days in a row, it will appear as being found twice.) Missing observations are those options that disappear on the day following the day on which they were purchased. (If an option remains missing for two days, it is counted as missing twice.) Expired observations are options that expire while being held as missing in the portfolio. Expired options are assigned their exercise value. Missing options are held until found, or their implied volatility is interpolated at the end of the month using a fit quadratic in moneyness and linear in maturity and the interaction between moneyness and maturity in log implied volatility.

reflects the cumulative return on the option throughout its time in the portfolio. ${ }^{1}$ All option portfolio returns are available on our websites. ${ }^{2}$

Statistics on missing options are displayed in Table 2. The problem of missing options is concentrated in the Berkeley database, where $19 \%$ of calls and $24 \%$ of puts go missing on the following trading day. While many of these options reappear before the end of the month, the process of carrying missing options on the books leads to more missing options at the end of the month than at the beginning. These two effects offset each other so that at the end of the month in the Berkeley database, $19 \%$ of calls and $24 \%$ of puts are interpolated based on a fitted-implied volatility surface. By contrast, in OptionMetrics, only $0.1 \%$ of all observations ever go missing.

The aggregation of options into portfolios, the daily rebalancing of the portfolios, and the adjustment for leverage have the effect of moderating the highly-skewed distribution of naked options held to maturity. In Table 3, the reported Jarque-Bera statistics, skewness, and excess kurtosis of the leverageadjusted portfolios indicate that the deviation of the return distributions from normality is moderate. Specifically, the ATM put portfolios have skewness of about -0.9 and excess kurtosis around 4 across all maturities. The ATM call portfolios have skewness near zero and excess kurtosis of about 0.8. By

${ }^{1}$ For example, if we invest 2 cents in a call and the value of our portfolio doubles from $\$ 1$ to $\$ 2$ while the call is not traded, the weight of the call becomes 0.01 . If the call then comes back and its price too has doubled, its weight is appropriately restored to 0.02 , giving the correct cumulative portfolio return of $100 \%$. In this way, we avoid any look-ahead bias and minimize the effect of missing options on the monthly portfolio return. Options that ultimately reappear do not introduce an error.

2 Websites: http://faculty.chicagobooth.edu/george.constantinides/index.htm; http://www.wiwi.uni-konstanz.de/ jackwerth; http://pages.stern.nyu.edu/ asavov/ 
Table 3

Average percentage monthly returns of the leverage-adjusted portfolios with daily rebalancing, April 1986 to January 2012

$$
\text { Calls Puts }
$$

$\begin{array}{lllllllllllll}\mathrm{K} / \mathrm{S} & 90.0 \% & 95.0 \% & 100.0 \% & 105.0 \% & 110.0 \% & \text { Hi-Lo } & 90.0 \% & 95.0 \% & 100.0 \% & 105.0 \% & 110.0 \% & \text { Hi-Lo }\end{array}$

\begin{tabular}{|c|c|c|c|c|c|c|c|c|c|c|c|c|}
\hline \multicolumn{13}{|c|}{ Average returns } \\
\hline 30 days & 0.49 & 0.42 & 0.21 & 0.03 & -0.02 & -0.51 & 2.18 & 1.66 & 1.07 & 0.80 & 0.75 & -1.43 \\
\hline (s.e.) & $(0.24)$ & $(0.24)$ & $(0.24)$ & $(0.23)$ & $(0.22)$ & $(0.17)$ & $(0.36)$ & $(0.32)$ & $(0.29)$ & $(0.27)$ & $(0.26)$ & $(0.20)$ \\
\hline 90 days & 0.51 & 0.44 & 0.37 & 0.31 & 0.21 & -0.30 & 1.15 & 1.10 & 0.91 & 0.81 & 0.74 & -0.40 \\
\hline (s.e.) & $(0.24)$ & $(0.24)$ & $(0.24)$ & $(0.24)$ & $(0.24)$ & $(0.11)$ & $(0.33)$ & $(0.31)$ & $(0.29)$ & $(0.27)$ & $(0.27)$ & $(0.14)$ \\
\hline $90-30$ & 0.03 & 0.02 & 0.16 & 0.28 & 0.23 & & -1.04 & -0.55 & -0.16 & 0.00 & -0.01 & \\
\hline (s.e.) & $(0.02)$ & $(0.02)$ & $(0.03)$ & $(0.06)$ & $(0.11)$ & & $(0.11)$ & $(0.07)$ & $(0.03)$ & $(0.02)$ & $(0.02)$ & \\
\hline \multicolumn{13}{|c|}{ Volatility } \\
\hline 30 days & 4.28 & 4.20 & 4.15 & 4.08 & 3.94 & 2.97 & 6.33 & 5.66 & 5.11 & 4.72 & 4.57 & 3.46 \\
\hline 90 days & 4.20 & 4.16 & 4.16 & 4.18 & 4.18 & 1.94 & 5.84 & 5.41 & 5.06 & 4.82 & 4.68 & 2.39 \\
\hline $90-30$ & 0.35 & 0.34 & 0.49 & 1.14 & 1.98 & & 1.95 & 1.23 & 0.54 & 0.42 & 0.42 & \\
\hline \multicolumn{13}{|c|}{ Skewness } \\
\hline 30 days & -0.26 & -0.19 & 0.02 & 0.58 & 1.39 & 1.28 & -1.57 & -1.24 & -0.89 & -0.63 & -0.51 & 1.64 \\
\hline 90 days & -0.21 & -0.11 & 0.03 & 0.25 & 0.47 & 1.42 & -1.16 & -1.02 & -0.86 & -0.70 & -0.61 & 1.43 \\
\hline $90-30$ & 1.95 & 0.48 & -0.30 & -0.69 & -0.15 & & 0.11 & 1.17 & 0.08 & -0.57 & -0.87 & \\
\hline
\end{tabular}

Excess kurtosis

\begin{tabular}{lllllllllllll}
\hline 30 days & 0.65 & 0.68 & 0.81 & 2.26 & 5.96 & 4.12 & 6.90 & 5.03 & 4.10 & 2.75 & 1.86 & 6.67 \\
90 days & 0.60 & 0.62 & 0.75 & 1.10 & 1.45 & 4.88 & 5.11 & 4.60 & 3.64 & 3.05 & 2.45 & 4.45 \\
$90-30$ & 9.84 & 3.71 & 3.09 & 1.77 & 5.11 & & 4.64 & 6.92 & 1.90 & 2.40 & 4.28 & \\
\hline
\end{tabular}

Jarque-Bera normality test $p$-value

\begin{tabular}{lllllllllllll}
\hline 30 days & 0.02 & 0.03 & 0.02 & 0.00 & 0.00 & 0.00 & 0.00 & 0.00 & 0.00 & 0.00 & 0.00 & 0.00 \\
90 days & 0.03 & 0.05 & 0.03 & 0.00 & 0.00 & 0.00 & 0.00 & 0.00 & 0.00 & 0.00 & 0.00 & 0.00 \\
$90-30$ & 0.00 & 0.00 & 0.00 & 0.00 & 0.00 & & 0.00 & 0.00 & 0.00 & 0.00 & 0.00 & \\
\hline
\end{tabular}

S\&P betas

\begin{tabular}{llllllllllllll}
\hline 30 days & 0.88 & 0.86 & 0.82 & $\begin{array}{l}0.71 \\
0.79\end{array}$ & 0.56 & -0.32 & 1.08 & 1.02 & 0.99 & 0.96 & 0.93 & -0.14 \\
\hline 90 & 0.74 & -0.13 & 1.06 & 1.03 & 1.00 & 0.97 & 0.95 & -0.11
\end{tabular}

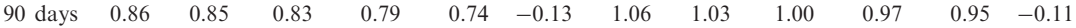

We omit portfolios with moneyness $0.925,0.975,1.025,1.075$ and maturity 60 days to conserve space. For comparison, the S\&P 500 has average return $0.86 \%$, volatility $4.57 \%$, skewness $\quad 0.82$, excess kurtosis 2.30 , and Jarque-Bera $p$-value 0.00 .

contrast, over the same period, the S\&P 500 Index has skewness of -0.8 and excess kurtosis of 2.3. The deep OTM put and call 30-day portfolios have the highest skewness ( -1.57 and 1.39) and highest excess kurtosis (6.90 and 5.96). Table 4 shows the same statistics for unadjusted portfolios. Adjusting for leverage tends to reduce skewness and excess kurtosis by an order of magnitude for OTM call and put portfolios. We also report distributional statistics for long-short strategies across moneyness and maturity, which capture the cross-sectional differences in average returns. The returns of these strategies tend to be significantly less volatile but somewhat farther from normal.

The leverage adjustment of the options in our portfolios aims to make the monthly index betas of these portfolios close to one. These betas need not 
Table 4

Average percentage monthly returns of the leverage-unadjusted portfolios with daily rebalancing, April 1986 to January 2012

$$
\text { Calls Puts }
$$

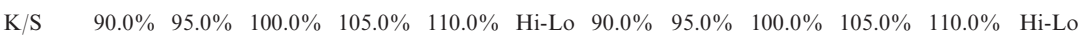

\begin{tabular}{lccccccccccccc}
\hline \multicolumn{10}{c}{ Average returns } \\
\hline 30 days & 0.2 & -1.4 & -3.9 & 7.9 & 12.4 & 12.2 & -50.6 & -40.5 & -28.4 & -12.5 & -7.0 & 43.5 \\
(s.e.) & $(2.1)$ & $(3.3)$ & $(8.5)$ & $(26.6)$ & $(27.3)$ & $(26.3)$ & $(7.8)$ & $(9.6)$ & $(5.9)$ & $(3.6)$ & $(2.5)$ & $(6.4)$ \\
90 days & 0.7 & 0.1 & 0.4 & 6.1 & 2.7 & 1.9 & -14.3 & -16.3 & -11.9 & -8.5 & -5.7 & 8.6 \\
$($ s.e.) & $(1.7)$ & $(2.4)$ & $(4.1)$ & $(7.8)$ & $(9.3)$ & $(8.1)$ & $(6.7)$ & $(4.4)$ & $(3.6)$ & $(2.7)$ & $(2.2)$ & $(5.3)$ \\
$90-30$ & 0.5 & 1.6 & 4.4 & -1.8 & -9.7 & & 36.2 & 24.1 & 16.4 & 3.9 & 1.3 & \\
(s.e.) & $(0.4)$ & $(1.0)$ & $(5.1)$ & $(22.1)$ & $(22.2)$ & & $(4.4)$ & $(6.1)$ & $(2.7)$ & $(1.1)$ & $(0.5)$ \\
\hline
\end{tabular}

\begin{tabular}{lrrrrrrrrrrrr}
\hline \multicolumn{10}{c}{ Volatility } \\
\hline 30 days & 37 & 59 & 151 & 469 & 480 & 464 & 137 & 170 & 103 & 64 & 44 & 113 \\
90 days & 31 & 43 & 72 & 138 & 164 & 144 & 118 & 78 & 64 & 48 & 38 & 93 \\
$90-30$ & 7 & 18 & 90 & 389 & 391 & & 77 & 107 & 47 & 21 & 9 & \\
\hline
\end{tabular}

\begin{tabular}{lrrrrrrrrrrrr}
\hline \multicolumn{10}{c}{ Skewness } \\
\hline 30 days & 0 & 1 & 5 & 10 & 9 & 9 & 6 & 9 & 5 & 2 & 1 \\
90 days & 0 & 1 & 3 & 5 & 4 & 5 & 8 & 5 & 3 & 2 & 1 & -11 \\
$90-30$ & -1 & -2 & -6 & -12 & -11 & & -7 & -10 & -7 & -3 & -1 & \\
\hline
\end{tabular}

\begin{tabular}{lllrrrrrrrrrr}
\hline 10 & \multicolumn{10}{c}{ Excess kurtosis } \\
\hline 30 days & 1 & 6 & 40 & 125 & 97 & 102 & 55 & 114 & 56 & 11 & 4 \\
90 days & 1 & 6 & 24 & 40 & 31 & 37 & 112 & 46 & 24 & 7 & 4 & 166 \\
$90-30$ & 3 & 9 & 53 & 175 & 150 & & 81 & 118 & 79 & 19 & 4 \\
\hline
\end{tabular}

Jarque-Bera normality test $p$-value

\begin{tabular}{lllllllllllll}
\hline 30 days & 0 & 0 & 0 & 0 & 0 & 0 & 0 & 0 & 0 & 0 & 0 & 0 \\
90 days & 0 & 0 & 0 & 0 & 0 & 0 & 0 & 0 & 0 & 0 & 0 & 0 \\
$90-30$ & 0 & 0 & 0 & 0 & 0 & & 0 & 0 & 0 & 0 & 0 & 0 \\
\hline
\end{tabular}

\begin{tabular}{rrrrrrrrrrrrrr}
\hline 10 & S\&P betas \\
\hline 30 days & 7 & 10 & 18 & 33 & 35 & 28 & -18 & -22 & -17 & -12 & -8 \\
9 \\
90 days & 6 & 8 & 11 & 17 & 19 & 13 & -17 & -13 & -11 & -9 & -7 & 9 \\
\hline
\end{tabular}

We omit portfolios with moneyness $0.925,0.975,1.025,1.075$ and maturity 60 days to conserve space. For comparison, the S\&P 500 has an average return of $0.86 \%$, volatility of $4.57 \%$, skewness of $\quad 0.82$, excess kurtosis of 2.30, and Jarque-Bera $p$-value of 0.00 .

exactly equal one for two reasons. First, we leverage-adjust options using the elasticity implied by the BSM model, which may not be the exact elasticity, if the BSM model is not applicable to these options. Second, we leverage-adjust daily returns that we subsequently compound into monthly returns; this is not the same as leverage-adjusting monthly returns. Indeed, the call portfolio monthly betas reported in Table 3 are lower than one and as low as 0.56 while the put portfolio betas range from 0.93 to 1.08 . These discrepancies are not a cause for concern because in the pricing tests we explicitly adjust for the market beta instead of presuming that it equals one. Table 3 also displays the average returns of the call and put portfolios. Both the 30-day and 90-day OTM call portfolios have higher average returns than the corresponding ITM 
calls. Also 30-day and 90-day OTM put portfolios have higher average returns than the corresponding ITM puts (recall that put portfolios have a short position in puts).

In Table 5, we examine the effect of our leverage adjustment on the nonlinearity of option portfolio returns. We run regressions of both our leverageadjusted and leverage-unadjusted returns on the return and the squared return of the S\&P 500 Index. As expected, the unadjusted portfolios have bigger loadings on the index return that are increasing in moneyness. The differences in loadings on the squared index return are even more substantial. For our leverage-adjusted put portfolios, almost all are within one standard error from zero, none are more than two, and point estimates are often negative. As for the leverage-unadjusted returns, these loadings range from 11 to 195, and all are between two and four standard errors away from zero. For the call returns, the differences in magnitudes are similar: the adjusted returns have loadings between 1 and 3 versus 16 to 433 for the unadjusted returns,

Table 5

Regressions of option portfolio returns on the S\&P 500 return and the squared S\&P 500 return, leverageadjusted (Panel A) and leverage-unadjusted portfolios (Panel B)

\begin{tabular}{|c|c|c|c|c|c|c|c|c|c|c|}
\hline \multirow[b]{2}{*}{$\mathrm{K} / \mathrm{S}$} & \multicolumn{5}{|c|}{ Calls } & \multicolumn{5}{|c|}{ Puts } \\
\hline & $90.0 \%$ & $95.0 \%$ & $100.0 \%$ & $105.0 \%$ & $110.0 \%$ & $90.0 \%$ & $95.0 \%$ & $100.0 \%$ & $105.0 \%$ & $110.0 \%$ \\
\hline \multicolumn{11}{|c|}{$\begin{array}{l}\text { Panel A: Leverage-adjusted option portfolios } \\
\text { Loading on S\&P } 500 \text { return }\end{array}$} \\
\hline $\begin{array}{l}30 \text { days } \\
\text { (s.e.) } \\
90 \text { days } \\
\text { (s.e.) }\end{array}$ & $\begin{array}{c}0.91 \\
(0.02) \\
0.89 \\
(0.02)\end{array}$ & $\begin{array}{c}0.89 \\
(0.03) \\
0.88 \\
(0.03)\end{array}$ & $\begin{array}{c}0.86 \\
(0.03) \\
0.88 \\
(0.03)\end{array}$ & $\begin{array}{c}0.77 \\
(0.04) \\
0.85 \\
(0.04)\end{array}$ & $\begin{array}{c}0.64 \\
(0.06) \\
0.80 \\
(0.04)\end{array}$ & $\begin{array}{c}1.01 \\
(0.06) \\
1.01 \\
(0.05)\end{array}$ & $\begin{array}{c}0.97 \\
(0.05) \\
0.99 \\
(0.04)\end{array}$ & $\begin{array}{c}0.98 \\
(0.04) \\
0.98 \\
(0.04)\end{array}$ & $\begin{array}{c}0.96 \\
(0.03) \\
0.96 \\
(0.03)\end{array}$ & $\begin{array}{c}0.94 \\
(0.03) \\
0.95 \\
(0.03)\end{array}$ \\
\hline \multicolumn{11}{|c|}{ Loading on the squared S\&P 500 return } \\
\hline $\begin{array}{l}30 \text { days } \\
\text { (s.e.) } \\
90 \text { days } \\
\text { (s.e.) }\end{array}$ & $\begin{array}{c}1.06 \\
(0.48) \\
1.11 \\
(0.44)\end{array}$ & $\begin{array}{c}1.28 \\
(0.42) \\
1.38 \\
(0.42)\end{array}$ & $\begin{array}{c}1.75 \\
(0.40) \\
1.72 \\
(0.38)\end{array}$ & $\begin{array}{c}2.33 \\
(0.44) \\
2.15 \\
(0.39)\end{array}$ & $\begin{array}{c}3.00 \\
(0.65) \\
2.31 \\
(0.48)\end{array}$ & $\begin{array}{c}2.62 \\
(1.36) \\
1.86 \\
(1.00)\end{array}$ & $\begin{array}{c}1.69 \\
(1.26) \\
1.26 \\
(1.00)\end{array}$ & $\begin{array}{c}0.72 \\
(0.98) \\
0.69 \\
(0.90)\end{array}$ & $\begin{array}{c}0.00 \\
(0.78) \\
0.24 \\
(0.85)\end{array}$ & $\begin{array}{c}0.20 \\
(0.67) \\
0.02 \\
(0.74)\end{array}$ \\
\hline
\end{tabular}

Panel B: Leverage-unadjusted option portfolios Loading on S\&P 500 return

\begin{tabular}{lcccccccccc}
\hline 30 days & 7.77 & 11.85 & 22.67 & 43.72 & 47.20 & 13.31 & 15.45 & 14.22 & 11.49 & 8.44 \\
(s.e.) & $(0.30)$ & $(0.79)$ & $(3.82)$ & $(13.93)$ & $(13.59)$ & $(1.97)$ & $(2.40)$ & $(1.09)$ & $(0.61)$ & $(0.37)$ \\
90 days & 6.61 & 9.04 & 13.63 & 21.56 & 24.08 & 13.48 & 11.44 & 10.55 & 8.95 & 7.45 \\
$($ s.e. $)$ & $(0.23)$ & $(0.53)$ & $(1.39)$ & $(3.36)$ & $(3.68)$ & $(1.46)$ & $(0.73)$ & $(0.54)$ & $(0.39)$ & $(0.29)$ \\
\hline
\end{tabular}

Loading on the squared S\&P 500 return

\begin{tabular}{lllllllllll}
\hline 30 days & 20.06 & 47.48 & 154.31 & 393.36 & 433.24 & 195.22 & 250.74 & 120.46 & 36.53 & 12.80 \\
(s.e.) & $(3.40)$ & $(10.50)$ & $(59.88)$ & $(200.64)$ & $(203.07)$ & $(36.38)$ & $(77.84)$ & $(32.64)$ & $(10.55)$ & $(5.79)$ \\
90 days & 16.30 & 32.77 & 70.09 & 143.07 & 165.92 & 157.22 & 85.31 & 52.65 & 22.77 & 11.00 \\
(s.e.) & $(2.49)$ & $(7.26)$ & $(21.74)$ & $(54.25)$ & $(58.74)$ & $(57.28)$ & $(20.90)$ & $(12.27)$ & $(5.76)$ & $(4.10)$ \\
\hline
\end{tabular}

The leverage-adjusted portfolios use elasticity scaling, the leverage-unadjusted portfolio do not. The sample covers April 1986 through January 2012. 
though in this case the adjusted return loadings also tend to be more than two standard errors away from zero.

\subsection{Econometric modeling}

We estimate the factor premia from the cross-section of option returns and test whether these premia explain the cross-section of option returns. As a stricter criterion, we also estimate the factor premia from the cross-section of the standard Fama-French 25 portfolios and test whether these premia explain the cross-section of option returns, thereby investigating the degree of integration or differential liquidity of the equity and option markets. ${ }^{3}$ Our approach consists of several stages and may potentially introduce unaccounted errors-in-variables.

We deal with this issue by reporting bootstrapped standard errors and $p$ values calculated as follows. We calculate the factor betas of our option portfolios. Then we regress the average excess returns of the portfolios on their betas and record the estimated premia. In the second cross-sectional stage, we impose the restriction that the intercept, corresponding to the excess return on a zero-beta asset, is equal to zero. This restriction increases the power of our tests and ensures that we do not obtain spurious results whereby small differences in factor loadings across correlated portfolios, together with a large premium, appear to fit the cross-section of option returns. We calculate a $J$-statistic to test the hypothesis that all portfolio pricing errors are zero.

To calculate our bootstrapped standard errors, we draw 10,000 simulations under the null of zero pricing error for each of our portfolios. Specifically, we subtract the estimated pricing errors from the returns of our portfolios and draw a sample of equal length to our underlying sample with replacement. Our sampling method assumes that returns are uncorrelated across months but allows for cross-sectional correlation. We then perform our two-stage pricing test and calculate a new set of betas, premia, and alphas for each run. We calculate bootstrapped standard errors as the standard deviation of the quantities in question. We calculate bootstrapped $p$-values by comparing our actual $J$-statistic to the $J$-statistics drawn under the null of zero alphas in the bootstrapped runs.

\section{Empirical Results for Unconditional Crisis-Related Factor Models}

As a preliminary step in our investigation, we allow for the S\&P 500 Index to be the sole factor, thereby testing the CAPM. The results are displayed in the first two columns of Table 6 and the two left-most panels of Figure 5. The alphas of all call portfolios are negative and statistically significant, irrespective of whether the factor premium is estimated from the universe of stocks or

\footnotetext{
3 This approach is in the spirit of the recommendation in Lewellen, Nagel, and Shanken (2010) to expand the set of test assets to include other portfolios.
} 
Table 6

Asset pricing tests with selected factors, April 1986 to January 2012

Factor premia

\begin{tabular}{|c|c|c|c|c|c|c|c|c|c|c|}
\hline \multirow{5}{*}{$\begin{array}{l}1^{\text {st }} \text { factor } \\
\text { Stock-based } \\
\text { Option-based } \\
\text { Difference }\end{array}$} & \\
\hline & \multicolumn{2}{|c|}{$S \& P$} & \multicolumn{2}{|c|}{$S \& P$} & \multicolumn{2}{|c|}{$S \& P$} & \multicolumn{2}{|c|}{$S \& P$} & \multicolumn{2}{|c|}{$S \& P$} \\
\hline & 0.63 & $(0.30)$ & 0.51 & $(0.28)$ & 0.57 & $(0.30)$ & 0.53 & $(0.27)$ & 0.48 & $(0.30)$ \\
\hline & 0.46 & $(0.27)$ & 0.55 & $(0.41)$ & 0.47 & $(0.32)$ & 0.36 & $(0.28)$ & 0.62 & $(0.59)$ \\
\hline & 0.17 & $(0.16)$ & -0.04 & $(0.33)$ & 0.11 & $(0.23)$ & 0.17 & $(0.17)$ & -0.14 & $(0.59)$ \\
\hline \multicolumn{3}{|l|}{$2^{\text {nd }}$ factor } & \multicolumn{2}{|c|}{ Jump } & \multicolumn{2}{|c|}{ Volatility Jump } & \multicolumn{2}{|c|}{ Volatility } & \multicolumn{2}{|c|}{ Liquidity } \\
\hline \multirow{4}{*}{$\begin{array}{l}\text { Stock-based } \\
\text { Option-based } \\
\text { Difference }\end{array}$} & & & 1.27 & $(0.78)$ & -3.73 & $(1.70)$ & -1.04 & $(0.84)$ & 5.81 & $(2.19)$ \\
\hline & & & 2.32 & $(1.31)$ & -4.98 & $(3.10)$ & -1.87 & $(0.48)$ & 13.91 & (11.37) \\
\hline & & & -1.05 & $(1.50)$ & 1.24 & $(3.41)$ & 0.83 & $(0.90)$ & -8.10 & (11.47) \\
\hline & \multicolumn{10}{|c|}{$\begin{array}{c}\text { Call portfolios } \\
\text { Betas (for } 2^{\text {nd }} \text { factor) }\end{array}$} \\
\hline 30 days, $95 \%$ & 0.86 & $(0.04)$ & -0.19 & $(0.05)$ & 0.06 & $(0.02)$ & 0.13 & $(0.05)$ & -0.03 & $(0.03)$ \\
\hline 30 days, $105 \%$ & 0.71 & $(0.06)$ & -0.28 & $(0.08)$ & 0.12 & $(0.04)$ & 0.29 & $(0.06)$ & -0.06 & $(0.03)$ \\
\hline 90 days, $95 \%$ & 0.85 & $(0.04)$ & -0.19 & $(0.05)$ & 0.07 & $(0.02)$ & 0.14 & $(0.05)$ & -0.03 & $(0.03)$ \\
\hline \multirow[t]{2}{*}{90 days, $105 \%$} & 0.79 & $(0.05)$ & -0.27 & $(0.07)$ & 0.12 & $(0.03)$ & 0.25 & $(0.06)$ & -0.04 & $(0.03)$ \\
\hline & \multicolumn{10}{|c|}{ Alphas (using stock-based premia) } \\
\hline 30 days, $95 \%$ & -0.45 & $(0.17)$ & -0.14 & $(0.20)$ & -0.19 & $(0.22)$ & -0.27 & $(0.16)$ & -0.17 & $(0.22)$ \\
\hline 30 days, $105 \%$ & -0.74 & $(0.20)$ & -0.34 & $(0.29)$ & -0.29 & $(0.31)$ & -0.45 & $(0.28)$ & -0.31 & $(0.28)$ \\
\hline 90 days, $95 \%$ & -0.42 & $(0.17)$ & -0.10 & $(0.21)$ & -0.15 & $(0.22)$ & -0.24 & $(0.16)$ & -0.12 & $(0.22)$ \\
\hline \multirow[t]{2}{*}{90 days, $105 \%$} & -0.51 & $(0.19)$ & -0.12 & $(0.27)$ & -0.07 & $(0.29)$ & -0.25 & $(0.25)$ & -0.16 & $(0.25)$ \\
\hline & \multicolumn{10}{|c|}{ Alphas (using option-based premia) } \\
\hline 30 days, $95 \%$ & -0.31 & $(0.07)$ & 0.02 & $(0.07)$ & -0.01 & $(0.08)$ & 0.00 & $(0.03)$ & -0.09 & $(0.15)$ \\
\hline 30 days, $105 \%$ & -0.62 & $(0.14)$ & -0.07 & $(0.09)$ & -0.04 & $(0.09)$ & -0.05 & $(0.06)$ & 0.05 & $(0.23)$ \\
\hline 90 days, $95 \%$ & -0.28 & $(0.07)$ & 0.06 & $(0.06)$ & 0.03 & $(0.06)$ & 0.03 & $(0.03)$ & 0.00 & $(0.13)$ \\
\hline 90 days, $105 \%$ & -0.38 & $(0.12)$ & 0.13 & $(0.06)$ & 0.17 & $(0.08)$ & 0.12 & $(0.04)$ & 0.05 & $(0.16)$ \\
\hline
\end{tabular}

Put portfolios

Betas (for $2^{\text {nd }}$ factor)

\begin{tabular}{|c|c|c|c|c|c|c|c|c|c|c|}
\hline 30 days, $95 \%$ & 1.03 & $(0.06)$ & 0.23 & $(0.15)$ & -0.12 & $(0.05)$ & -0.42 & $(0.12)$ & 0.04 & $(0.06)$ \\
\hline 30 days, $105 \%$ & 0.96 & $(0.04)$ & 0.00 & $(0.10)$ & -0.02 & $(0.03)$ & -0.11 & $(0.08)$ & -0.02 & $(0.04)$ \\
\hline 90 days, $95 \%$ & 1.04 & $(0.05)$ & 0.16 & $(0.12)$ & -0.09 & $(0.05)$ & -0.33 & $(0.10)$ & 0.02 & $(0.05)$ \\
\hline 90 days, $105 \%$ & 0.97 & $(0.04)$ & 0.02 & $(0.10)$ & -0.03 & $(0.03)$ & -0.14 & $(0.08)$ & -0.01 & $(0.04)$ \\
\hline \multicolumn{11}{|c|}{ Alphas (using stock-based premia) } \\
\hline 30 days, $95 \%$ & 0.66 & $(0.21)$ & 0.54 & $(0.34)$ & 0.33 & $(0.33)$ & 0.48 & $(0.41)$ & 0.61 & $(0.30)$ \\
\hline 30 days, $105 \%$ & -0.14 & $(0.16)$ & -0.02 & $(0.19)$ & -0.14 & $(0.19)$ & -0.12 & $(0.18)$ & 0.10 & $(0.23)$ \\
\hline 90 days, $95 \%$ & 0.11 & $(0.18)$ & 0.06 & $(0.27)$ & -0.12 & $(0.26)$ & -0.02 & $(0.32)$ & 0.14 & $(0.25)$ \\
\hline 90 days, $105 \%$ & -0.14 & $(0.16)$ & -0.05 & $(0.20)$ & -0.19 & $(0.19)$ & -0.14 & $(0.19)$ & 0.08 & $(0.23)$ \\
\hline \multicolumn{11}{|c|}{ Alphas (using option-based premia) } \\
\hline 30 days, $95 \%$ & 0.84 & $(0.14)$ & 0.27 & $(0.10)$ & 0.28 & $(0.09)$ & 0.27 & $(0.06)$ & 0.17 & $(0.25)$ \\
\hline 30 days, $105 \%$ & 0.03 & $(0.04)$ & -0.07 & $(0.10)$ & -0.05 & $(0.11)$ & -0.06 & $(0.04)$ & 0.09 & $(0.16)$ \\
\hline 90 days, $95 \%$ & 0.28 & $(0.10)$ & -0.15 & $(0.06)$ & -0.12 & $(0.08)$ & -0.16 & $(0.04)$ & -0.19 & $(0.17)$ \\
\hline 90 days, $105 \%$ & 0.02 & $(0.04)$ & -0.11 & $(0.08)$ & -0.13 & $(0.06)$ & -0.11 & $(0.04)$ & 0.04 & $(0.14)$ \\
\hline \multicolumn{11}{|c|}{ Stock portfolio test statistics (using stock-based premia) } \\
\hline R.m.s. (p) & 0.25 & $(0.00)$ & 0.24 & $(0.00)$ & 0.23 & $(0.00)$ & 0.25 & $(0.00)$ & 0.21 & $(0.01)$ \\
\hline \multicolumn{11}{|c|}{ Option portfolio test statistics (using stock-based premia) } \\
\hline R.m.s. (p) & 0.47 & $(0.01)$ & 0.24 & $(0.05)$ & 0.20 & $(0.39)$ & 0.29 & $(0.01)$ & 0.28 & $(0.13)$ \\
\hline \multicolumn{11}{|c|}{ Option portfolio test statistics (using option-based premia) } \\
\hline R.m.s. (p) & 0.44 & $(0.00)$ & 0.13 & $(0.21)$ & 0.13 & $(0.51)$ & 0.13 & $(0.08)$ & 0.13 & $(0.61)$ \\
\hline
\end{tabular}

The stock-based (option-based) results estimate factor premia from the 25 Fama-French portfolios (54 option portfolios). We report betas (factor loadings) and pricing errors (alphas) for four representative portfolios (the rest fall in between). We run two-stage OLS with 10,000 bootstrap simulations. We report bootstrapped standard errors, root-mean-squared pricing errors, and a bootstrapped $p$-value for the joint hypothesis that all pricing errors are zero. 


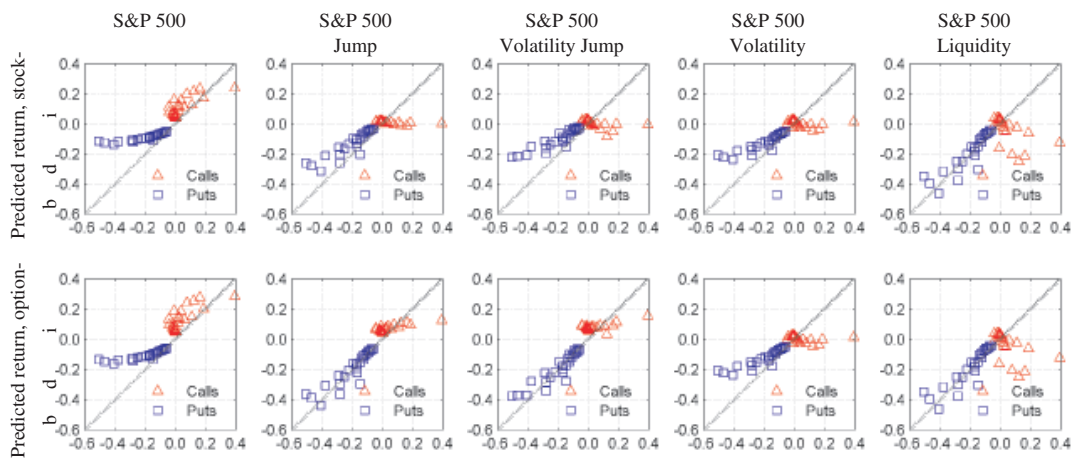

Figure 5

Predicted versus average returns, April 1986 to January 2012.

We plot the predicted versus sample average returns of the 54 option portfolios based on the five models in Table 6, with stock-based factor premia (top row) and option-based factor premia (bottom row).

the universe of options. Thus calls are overpriced according to the CAPM. The alphas of the 30-day OTM put portfolios are positive and statistically significant, irrespective of whether the market premium is estimated from the universe of stocks or the universe of options. Thus the short-maturity OTM puts are also overpriced according to the CAPM (recall that the put portfolios have a short position in puts). The alphas of most of the other put portfolios are not statistically different from zero. The monthly rms pricing error is 44$47 \mathrm{bps}$ and the $p$-value is $1 \%$ or less. These results confirm well-known results and, in particular, the apparent overpricing of OTM puts.

In the first two columns of Table 7, we contrast the above results with tests of the CAPM using leverage-unadjusted option returns. The p-value is $34 \%$ (using stock-based premia) or $32 \%$ (using option-based premia) and the CAPM is not rejected even though the monthly rms error is $1200 \mathrm{bps}$. This result illustrates the major advantage of using leverage-adjusted portfolio returns.

There are only two sizeable principal components in the covariance structure of the option portfolios, accounting for $89 \%$ and $10 \%$ of the variance, respectively. This feature of the covariance structure guides our test design. In this section, we limit the pricing model to at most two factors at a time, with the market proxied by the S\&P 500 Index being always the first factor. Thus with each model we test one new factor at a time. In the next section, we also investigate three-factor models and conditional models.

In our broad quest for factors that explain the cross-section of index option returns, we seek factors and their associated premia estimated from the universe of index options (along with the market factor and the equity market premium) that explain, at least in part, the variation across moneyness (the level and slope) and maturity of index option returns. Of all the factors we consider, the crisis-related factors, Jump, Volatility Jump, Volatility, and 
Table 7

Asset pricing tests on leverage-unadjusted portfolios with selected factors, April 1986 to January 2012

Factor premia

\begin{tabular}{|c|c|c|c|c|c|c|c|c|c|c|}
\hline \multirow{5}{*}{$\begin{array}{l}1^{\text {st }} \text { factor } \\
\text { Stock-based } \\
\text { Option-based } \\
\text { Difference }\end{array}$} & \\
\hline & \multicolumn{2}{|c|}{$S \& P$} & \multicolumn{2}{|c|}{$S \& P$} & \multicolumn{2}{|c|}{$S \& P$} & \multicolumn{2}{|c|}{$S \& P$} & \multicolumn{2}{|c|}{$S \& P$} \\
\hline & 0.63 & $(0.30)$ & 0.51 & $(0.28)$ & 0.57 & $(0.31)$ & 0.53 & $(0.27)$ & 0.48 & $(0.30)$ \\
\hline & 0.75 & $(0.33)$ & 0.92 & $(0.61)$ & 1.19 & $(0.58)$ & 1.03 & $(0.48)$ & 0.86 & $(0.50)$ \\
\hline & -0.12 & $(0.30)$ & -0.41 & $(0.53)$ & -0.62 & $(0.51)$ & -0.50 & $(0.36)$ & -0.38 & $(0.44)$ \\
\hline \multicolumn{3}{|l|}{$2^{\text {nd }}$ factor } & \multicolumn{2}{|c|}{ Jump } & \multicolumn{2}{|c|}{ Volatility Jump } & \multicolumn{2}{|c|}{ Volatility } & \multicolumn{2}{|c|}{ Liquidity } \\
\hline \multirow{4}{*}{$\begin{array}{l}\text { Stock-based } \\
\text { Option-based } \\
\text { Difference }\end{array}$} & & & 1.27 & $(0.79)$ & -3.73 & $(1.71)$ & -1.04 & $(0.85)$ & 5.81 & $(2.17)$ \\
\hline & & & 1.60 & $(2.37)$ & -5.34 & (4.92) & -1.52 & $(0.84)$ & 3.69 & $(4.52)$ \\
\hline & & & -0.33 & $(2.44)$ & 1.61 & $(5.05)$ & 0.48 & $(1.03)$ & 2.12 & $(5.07)$ \\
\hline & \multicolumn{10}{|c|}{$\begin{array}{l}\text { Call portfolios } \\
\text { Betas (for } 2^{\text {nd }} \text { factor) }\end{array}$} \\
\hline 30 days, $95 \%$ & 10.54 & $(0.94)$ & -2.79 & $(1.04)$ & 0.89 & $(0.40)$ & 3.98 & $(1.21)$ & -0.14 & $(0.56)$ \\
\hline 30 days, $105 \%$ & 32.22 & $(11.21)$ & -15.23 & $(6.81)$ & 6.60 & $(2.92)$ & 26.93 & $(10.38)$ & -6.41 & (4.37) \\
\hline 90 days, $95 \%$ & 8.15 & $(0.65)$ & -2.04 & $(0.71)$ & 0.70 & $(0.27)$ & 2.77 & $(0.89)$ & -0.21 & $(0.37)$ \\
\hline \multirow[t]{2}{*}{90 days, $105 \%$} & 17.61 & (3.13) & -6.91 & (2.39) & 2.96 & $(1.16)$ & 12.69 & (4.66) & -1.61 & (1.38) \\
\hline & \multicolumn{10}{|c|}{ Alphas (using stock-based premia) } \\
\hline 30 days, $95 \%$ & -8.52 & $(2.59)$ & -4.14 & $(3.26)$ & -4.96 & (3.34) & -4.48 & $(3.82)$ & -6.09 & $(3.46)$ \\
\hline 30 days, $105 \%$ & -12.51 & $(19.72)$ & 8.21 & $(25.81)$ & 11.05 & $(25.72)$ & 10.38 & $(31.85)$ & 28.42 & $(31.45)$ \\
\hline 90 days, $95 \%$ & -5.36 & $(1.86)$ & -2.11 & $(2.32)$ & -2.58 & $(2.42)$ & -2.51 & $(2.67)$ & -2.93 & $(2.47)$ \\
\hline \multirow[t]{2}{*}{90 days, $105 \%$} & -5.28 & $(6.19)$ & 4.49 & $(8.34)$ & 5.48 & $(8.90)$ & 5.81 & $(12.61)$ & 6.45 & $(9.37)$ \\
\hline & \multicolumn{10}{|c|}{ Alphas (using option-based premia) } \\
\hline 30 days, $95 \%$ & -9.75 & $(2.38)$ & -7.92 & $(4.35)$ & -10.45 & $(4.32)$ & -9.01 & (3.48) & -10.45 & $(4.71)$ \\
\hline 30 days, $105 \%$ & -16.28 & $(10.61)$ & -2.09 & $(8.61)$ & -1.38 & $(8.55)$ & -0.83 & (7.44) & 1.50 & (12.46) \\
\hline 90 days, $95 \%$ & -6.31 & $(1.90)$ & -5.05 & (3.48) & -6.82 & $(3.26)$ & -6.07 & $(2.78)$ & -6.53 & (3.40) \\
\hline 90 days, $105 \%$ & -7.34 & $(4.21)$ & -1.40 & $(5.45)$ & -2.04 & $(5.31)$ & -0.67 & $(5.05)$ & -3.94 & $(5.89)$ \\
\hline
\end{tabular}

Put portfolios

Betas (for $2^{\text {nd }}$ factor)

\begin{tabular}{lrlrrrrrrrr}
\hline 30 days, 95\% & -21.40 & $(6.44)$ & -18.53 & $(12.22)$ & 2.56 & $(2.90)$ & 16.71 & $(8.32)$ & -6.41 & $(4.02)$ \\
30 days, 105\% & -12.20 & $(0.93)$ & 0.36 & $(1.70)$ & -1.04 & $(0.42)$ & 2.41 & $(0.88)$ & -0.56 & $(0.49)$ \\
90 days, 95\% & -13.57 & $(2.01)$ & -5.06 & $(3.93)$ & 0.88 & $(0.98)$ & 6.82 & $(2.31)$ & -2.04 & $(1.27)$ \\
90 days, $105 \%$ & -9.45 & $(0.54)$ & 0.17 & $(0.98)$ & -0.37 & $(0.28)$ & 1.89 & $(0.46)$ & -0.28 & $(0.31)$ \\
\hline
\end{tabular}

\begin{tabular}{|c|c|c|c|c|c|c|c|c|c|c|}
\hline \multirow{5}{*}{$\begin{array}{l}30 \text { days, } 95 \% \\
30 \text { days, } 105 \% \\
90 \text { days, } 95 \% \\
90 \text { days, } 105 \%\end{array}$} & \multicolumn{10}{|c|}{ Alphas (using stock-based premia) } \\
\hline & -27.14 & $(11.26)$ & -9.48 & $(24.15)$ & -19.98 & $(15.16)$ & -17.26 & (18.48) & 5.54 & $(22.56)$ \\
\hline & -5.01 & $(2.79)$ & -6.93 & (3.17) & -9.15 & $(3.35)$ & -4.49 & $(3.13)$ & -3.72 & $(3.20)$ \\
\hline & -7.96 & (3.84) & -4.10 & $(7.32)$ & -5.86 & $(5.14)$ & -4.39 & $(6.45)$ & 1.42 & $(7.02)$ \\
\hline & -2.80 & (1.89) & -4.17 & (1.94) & -4.58 & $(2.10)$ & -2.40 & $(2.15)$ & -2.68 & (2.07) \\
\hline \multicolumn{11}{|c|}{ Alphas (using option-based premia) } \\
\hline 30 days, $95 \%$ & -24.64 & $(12.28)$ & 2.68 & $(8.81)$ & -3.91 & $(11.45)$ & -3.58 & $(9.25)$ & -0.87 & (12.55) \\
\hline 30 days, $105 \%$ & -3.59 & $(3.59)$ & -2.02 & $(4.88)$ & -2.80 & $(5.17)$ & 2.03 & (3.48) & -0.34 & $(4.20)$ \\
\hline 90 days, $95 \%$ & -6.37 & (4.82) & 2.37 & $(3.67)$ & 3.50 & $(3.42)$ & 3.60 & $(1.86)$ & 1.96 & (3.64) \\
\hline 90 days, $105 \%$ & -1.70 & (2.64) & -0.36 & $(3.08)$ & 0.82 & $(2.77)$ & 2.65 & $(3.00)$ & 0.30 & (3.31) \\
\hline
\end{tabular}

\begin{tabular}{lccccccccccc}
\hline R.m.s. (p) & 0.25 & $(0.00)$ & 0.24 & $(0.00)$ & 0.23 & $(0.00)$ & 0.25 & $(0.00)$ & 0.21 & $(0.01)$ \\
\hline \multicolumn{7}{c}{ Option portfolio test statistics (using stock-based premia) } \\
\hline R.m.s. (p) & 12.24 & $(0.34)$ & 9.53 & $(0.61)$ & 11.52 & $(0.55)$ & 10.51 & $(0.53)$ & 12.65 & $(0.64)$ \\
\hline R.m.s. (p) & 12.08 & $(0.32)$ & 6.75 & $(0.61)$ & 7.24 & $(0.64)$ & 7.01 & $(0.56)$ & 7.54 & $(0.60)$
\end{tabular}

The stock-based (option-based) results estimate factor premia from the 25 Fama-French portfolios (54 option portfolios). We report betas (factor loadings) and pricing errors (alphas) for four representative portfolios (the rest fall in between). We run two-stage OLS with 10,000 bootstrap simulations. We report bootstrapped standard errors, root-mean-squared pricing errors, and bootstrapped $p$-values for the hypothesis that all pricing errors are zero. Standard errors in parentheses. 
Liquidity, are the only ones that meet this challenge. We thus concentrate on these factors, which can be consistently estimated from the universe of equities or options. ${ }^{4}$

Jump is defined as the sum of all daily returns of the S\&P 500 that are lower than $-4 \%$ within each month, zero if there are none; approximately $7 \%$ of the months have nonzero jump. Volatility Jump is defined as the sum of all daily increases in the ATM call portfolio implied volatility that are greater than $4 \%$, zero otherwise; approximately $10 \%$ of the months have nonzero Volatility Jump. Volatility is defined as the end-of-the-month ATM call portfolio implied volatility minus the beginning-of-the-month ATM call portfolio implied volatility; using instead the CBOE-provided VIX, a shorter timeseries does not significantly change the results. Finally, Liquidity is defined as the innovation of the market-wide liquidity factor proposed by Pastor and Stambaugh (2003) and provided by the Wharton Research Data Services. The factor correlations are displayed in Table 1 .

We show that the four crisis-related factors work reasonably well in explaining the cross-section of option returns, even when we impose the stricter standard of estimating the premium from the universe of equities. The first panel of Table 6 displays the risk premia, betas, alphas, and pricing errors for each of these factors. We expect Jump to earn a positive premium as assets whose prices fall with the market are risky. We expect Volatility Jump and Volatility to earn negative premia because assets that have high returns during periods of increased volatility provide a useful hedge. We also expect the Liquidity premium to be positive because assets that covary positively with Liquidity are risky. The premia estimated from the universe of equities have the right signs and are statistically significant but for Volatility. The premia estimated from the universe of options have the right signs, are not significantly different from zero (but for Volatility), and are not significantly different from their counterparts estimated from the universe of equities.

The second and third panels of Table 6 display the betas and alphas of call portfolios for selected moneyness and maturities. The Jump betas of the call portfolios are negative and statistically significant, consistent with the intuition that calls are protected from large price declines. The Jump betas of the put portfolios are not statistically significant but are positive, as to be expected, since our leverage-adjusted portfolios hold puts short, which exposes them to downside risk. The call portfolios have positive Volatility Jump and Volatility betas that are increasing both in magnitude and statistical

\footnotetext{
${ }^{4}$ We also explore a large number of alternative factors, namely, Market (equally-weighted), Size, Value, Momentum, Realized Volatility, Realized Volatility minus Implied Volatility, Implied Volatility Slope, Volume, Open Interest, OTM Put Volume, Bid-Ask Spread, Sentiment, SPF Dispersion, Retail Call Demand, Retail Put Demand, Default Spread, Term Spread, Sharpe Ratio, Riskfree Rate, Inflation, and GDP. We find that these factors improve option pricing only when we base the premia on the universe of options. The pricing performance deteriorates once we require equity-based premia. The results, reported in the Online Appendix, demonstrate that the task of finding factors with equity-based premia that can explain the cross-section of option portfolio returns is a non-trivial one.
} 
significance towards the OTM call portfolios. This is intuitive since buying calls, in general, and OTM calls in particular, is a positive bet on volatility. Conversely, selling puts is a negative bet on volatility and the put portfolios have negative betas that become larger and more statistically significant in the direction of the OTM put portfolios. The differential sign and variation across moneyness of the loadings of our portfolios with respect to Jump, Volatility Jump, and Volatility allow these factors to capture the variation in option portfolio returns. By comparison, the Liquidity betas of the option portfolios are generally small and insignificant.

Each of the four factors does a good job at pricing the level of call returns. None of the call alphas is statistically different from zero, irrespective of whether the premium is estimated from the universe of equities or the universe of options. The alphas of put returns drop to $4-28 \mathrm{bps}$ from up to $84 \mathrm{bps}$ when the premium is estimated from the universe of options; however, some alphas are statistically different from zero. Figure 5 illustrates these results. The predicted and actual average returns of our put portfolios are more strongly aligned under each of our four two-factor models than under the single-index model. Whereas the S\&P 500 Index generates almost no variation in predicted returns among put portfolios, our crisis factors are able to differentiate them regardless of whether the factor premium is estimated among stocks or options.

For Jump, Volatility Jump, Volatility, and Liquidity, the rms pricing error of the option returns is 24 bps ( $p$-value 5\%), 20 bps ( $p$-value 39\%), $29 \mathrm{bps}$ ( $p$-value $1 \%$ ), and 28 bps ( $p$-value 13\%), respectively, when the premium is estimated from the universe of equities and drops further to $13 \mathrm{bps}$ ( $p$-value $21 \%$ ), 13 bps ( $p$-value $51 \%$ ), 13 bps ( $p$-value $8 \%$ ), and 13 bps ( $p$-value $61 \%$ ), respectively, when the premium is estimated from the universe of options. These numbers contrast to the rms error of 47 bps obtained from the singlefactor model with the S\&P 500 Index as the only factor and premium estimated from the universe of equities. Thus, each of the factors, Jump and Volatility Jump, and, to a lesser extent, Volatility and Liquidity, is able to account for a large part of the level of option portfolio returns, even when their premium is estimated among equities.

In the Online Appendix, we report results for the portfolios without daily rebalancing. The point estimates become noisier as the portfolios are farther from normal. The pricing errors are higher, but the four crisis-related factors continue to improve pricing even with equity-based premia. We also report results when we focus on the OptionMetrics subsample, 1996-2012. Jump and Volatility continue to do well and Volatility Jump does well with an optionbased premium but less so with an equity-based premium. The ability of Liquidity to price the cross-section of options and equities is reduced, and the estimated premium is statistically different between the two markets. In a further robustness test reported in the Online Appendix, we omit the 1987 crash and the 2007-2009 financial crisis from the sample period of 1986-2012. 
As the crises comprise the most pronounced episodes for our Jump and Volatility Jump factors, their explanatory power is reduced, while Volatility remains strong. We view the crises as revealing important risks associated with options and therefore choose to focus on the full sample.

Frazzini and Pedersen (2011) argued that securities with embedded leverage have higher prices because they allow investors to take levered positions without borrowing. The results in Table 3 support this hypothesis. Both 30day and 90-day OTM call portfolios have lower average returns than the corresponding ITM calls. Also 30-day and 90-day OTM put portfolios have higher average returns than the corresponding ITM puts (recall that put portfolios have a short position in puts). The same results obtain in Table 6 when the alphas are adjusted for market beta. However, this pattern is weakened and, in some instances, reversed when we introduce Jump, Volatility Jump, Volatility, or Liquidity as a second factor. For example, the pattern is reversed in Table 6 for both call and put portfolios when the alphas are also adjusted for exposure to Liquidity with an option-based Liquidity premium. It appears that the returns of the OTM calls and puts are systematically related to market conditions.

Reiterating the importance of using adjusted returns, we compare the results to Table 7 where we use unadjusted returns. Few estimates are significant and the results are noisy. The $p$-values are $53 \%-64 \%$ and we cannot reject the pricing tests at all.

\section{Empirical Results for Unconditional 3-Factor and Conditional Models}

We have established that we cannot reject the hypothesis that any one of the crisis-related factors incorporating price jumps, volatility jumps, and liquidity (along with the market) explains the cross-sectional variation in option returns, even when the factor premia are constrained to equal the corresponding premia in the cross-section of equities. We explore whether we can further reduce the pricing errors and, in particular, reduce the alphas of portfolios that sell short-maturity OTM puts.

In the first extension, we consider a number of combinations of Jump, Volatility Jump, Volatility, and Liquidity (along with the market) as threefactor unconditional linear pricing models. The results are displayed in Table 8. With equity-based factor premia, none of the alphas is statistically significant. The pricing errors decrease from 20-29 bps for the two-factor models to $16-27$ bps for the three-factor models; the best-performing model has Volatility Jump and Liquidity as factors (along with the market). With option-based premia, the pricing errors decrease by 1 bp or less. We conclude that the extension to three-factor models is moderately valuable.

In the second extension, we consider conditional two-factor models where the premia are affine in the level of Liquidity. The results are displayed in Table 9. The conditional models do not lead to an improvement in overall fit 
Table 8

Three-factor model asset pricing tests with selected factors, April 1986 through January 2012

Factor premia

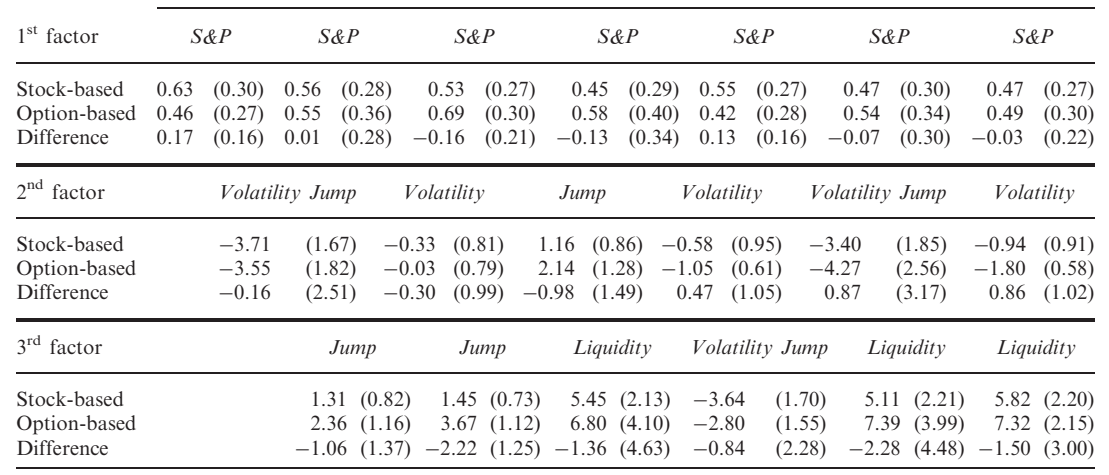

Call portfolios

Betas (for $2^{\text {nd }}$ factor)

\begin{tabular}{lllllllllllllll}
\hline 30 days, 95\% & 0.86 & $(0.04)$ & 0.01 & $(0.02)$ & 0.10 & $(0.03)$ & -0.19 & $(0.05)$ & 0.13 & $(0.04)$ & 0.06 & $(0.02)$ & 0.12 & $(0.05)$ \\
30 days, 105\% & 0.71 & $(0.06)$ & 0.07 & $(0.05)$ & 0.25 & $(0.05)$ & -0.27 & $(0.08)$ & 0.29 & $(0.04)$ & 0.12 & $(0.03)$ & 0.28 & $(0.06)$ \\
90 days, 95\% & 0.85 & $(0.04)$ & 0.01 & $(0.02)$ & 0.11 & $(0.03)$ & -0.19 & $(0.05)$ & 0.13 & $(0.04)$ & 0.07 & $(0.02)$ & 0.13 & $(0.05)$ \\
90 days, 105\% & 0.79 & $(0.05)$ & 0.06 & $(0.03)$ & 0.21 & $(0.05)$ & -0.27 & $(0.07)$ & 0.25 & $(0.04)$ & 0.12 & $(0.03)$ & 0.25 & $(0.06)$ \\
\hline
\end{tabular}

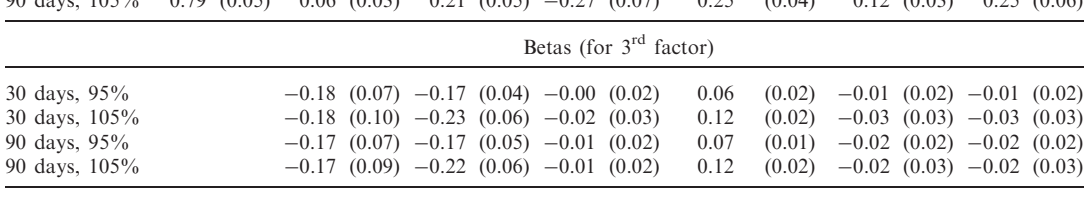

Alphas (using stock-based premia)

30 days, $95 \% \quad-0.45\left(\begin{array}{lllllllllllll}0.17) & -0.16 & (0.21) & -0.15 & (0.20) & -0.08 & (0.24) & -0.14 & (0.19) & -0.06 & (0.25) & -0.14 & (0.20)\end{array}\right.$

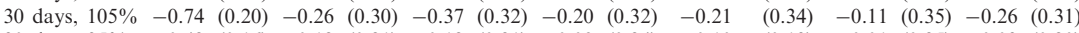

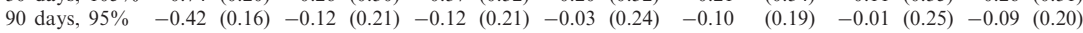
90 days, $105 \% \quad-0.51\left(\begin{array}{lllllllllllll}0.19) & -0.05 & (0.28) & -0.14 & (0.29) & -0.05 & (0.31) & -0.00 & (0.30) & 0.04 & (0.32) & -0.12 & (0.28)\end{array}\right.$

\begin{tabular}{|c|c|c|c|c|c|c|c|c|c|c|}
\hline \multirow{5}{*}{$\begin{array}{l}30 \text { days, } 95 \% \\
30 \text { days, } 105 \% \\
90 \text { days, } 95 \% \\
90 \text { days, } 105 \%\end{array}$} & \multicolumn{10}{|c|}{ Alphas (using option-based premia) } \\
\hline & -0.31 & $(0.07)$ & 0.03 & $(0.05)$ & $0.04(0.03)$ & $-0.02(0.04)$ & -0.01 & $(0.03)$ & $-0.05(0.06)$ & $-0.04(0.03)$ \\
\hline & -0.62 & $(0.14)$ & -0.07 & $(0.07)$ & $-0.08 \quad(0.06)$ & $-0.01 \quad(0.08)$ & -0.05 & $(0.06)$ & $0.01 \quad(0.08)$ & $0.01 \quad(0.07)$ \\
\hline & -0.28 & $(0.07)$ & 0.07 & $(0.05)$ & $0.08 \quad(0.03)$ & $0.04(0.05)$ & 0.03 & $(0.03)$ & $0.02(0.05)$ & $0.02(0.03)$ \\
\hline & -0.38 & $(0.12)$ & 0.13 & $(0.05)$ & $0.14(0.03)$ & $0.10(0.04)$ & 0.15 & $(0.03)$ & $0.12(0.07)$ & $0.09(0.03)$ \\
\hline \multicolumn{11}{|c|}{$\begin{array}{c}\text { Put portfolios } \\
\text { Betas (for } 2^{\text {nd }} \text { factor) }\end{array}$} \\
\hline 30 days, $95 \%$ & 1.03 & $(0.06)$ & -0.10 & $(0.08)$ & $-0.39(0.13)$ & $0.22(0.14)$ & -0.41 & $(0.13)$ & $-0.12(0.05)$ & $-0.42(0.12)$ \\
\hline 30 days, $105 \%$ & 0.96 & $(0.04)$ & -0.03 & $(0.05)$ & $-0.12(0.08)$ & $0.01 \quad(0.10)$ & -0.11 & $(0.09)$ & $-0.02(0.03)$ & $-0.12(0.08)$ \\
\hline 90 days, $95 \%$ & 1.04 & $(0.05)$ & -0.07 & $(0.07)$ & $-0.32(0.11)$ & $0.16(0.12)$ & -0.33 & $(0.11)$ & $-0.09 \quad(0.05)$ & $-0.34(0.10)$ \\
\hline 90 days, $105 \%$ & 0.97 & $(0.04)$ & -0.05 & $(0.05)$ & $-0.14(0.08)$ & $0.03(0.10)$ & -0.14 & $(0.09)$ & $-0.04(0.03)$ & $-0.15(0.08)$ \\
\hline \multicolumn{11}{|c|}{ Betas (for $3^{\text {rd }}$ factor) } \\
\hline 30 days, $95 \%$ & & & 0.08 & $(0.21)$ & $0.14(0.17)$ & $0.01 \quad(0.05)$ & -0.12 & $(0.04)$ & $0.01 \quad(0.05)$ & $0.00(0.05)$ \\
\hline 30 days, $105 \%$ & & & -0.04 & $(0.14)$ & $-0.02(0.11)$ & $-0.02(0.03)$ & -0.02 & $(0.03)$ & $-0.02(0.04)$ & $-0.03(0.04)$ \\
\hline 90 days, $95 \%$ & & & 0.06 & $(0.18)$ & $0.09(0.15)$ & $0.00 \quad(0.05)$ & -0.08 & $(0.03)$ & $0.00(0.05)$ & $-0.01 \quad(0.05)$ \\
\hline 90 days, $105 \%$ & & & -0.05 & $(0.14)$ & $-0.01 \quad(0.12)$ & $-0.02 \quad(0.04)$ & -0.03 & $(0.03)$ & $-0.02(0.04)$ & $-0.03(0.04)$ \\
\hline \multicolumn{11}{|c|}{ Alphas (using stock-based premia) } \\
\hline 30 days, $95 \%$ & 0.66 & $(0.21)$ & 0.34 & $(0.36)$ & $0.60(0.44)$ & $0.57 \quad(0.39)$ & 0.28 & $(0.47)$ & $0.41 \quad(0.39)$ & $0.58(0.48)$ \\
\hline 30 days, $105 \%$ & -0.14 & $(0.16)$ & -0.12 & $(0.19)$ & $-0.01 \quad(0.21)$ & $0.12(0.24)$ & -0.13 & $(0.20)$ & $0.06(0.24)$ & $0.10(0.25)$ \\
\hline 90 days, $95 \%$ & 0.11 & $(0.18)$ & -0.11 & $(0.28)$ & $0.10(0.34)$ & $0.12(0.32)$ & -0.15 & $(0.36)$ & $-0.01 \quad(0.32)$ & $0.12(0.39)$ \\
\hline 90 days, $105 \%$ & -0.14 & $(0.16)$ & -0.17 & $(0.20)$ & $-0.03 \quad(0.22)$ & $0.09 \quad(0.25)$ & -0.19 & $(0.22)$ & $0.01 \quad(0.25)$ & $0.08 \quad(0.26)$ \\
\hline
\end{tabular}


Table 8

Continued

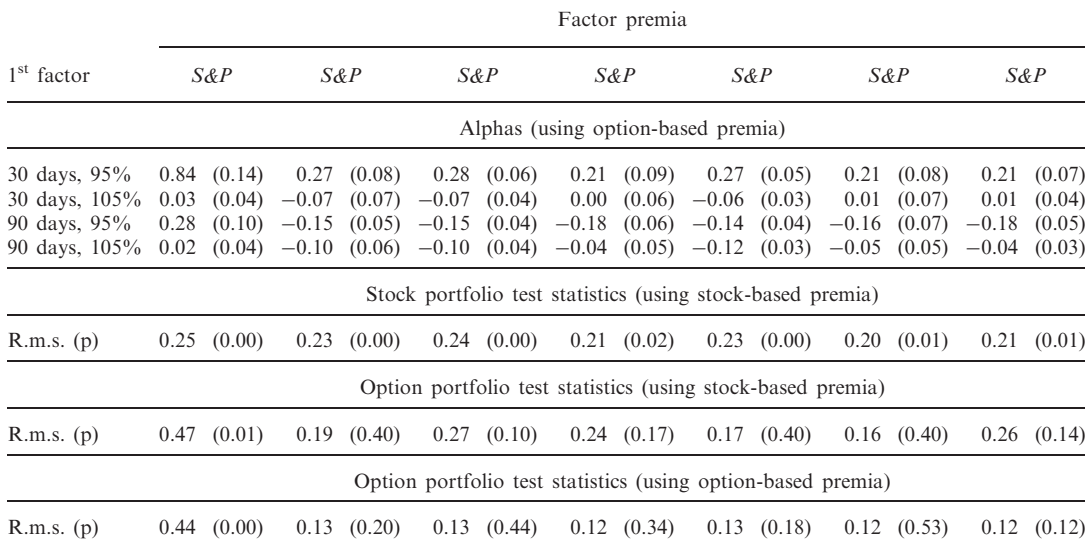

The stock-based results estimate the factor premia among the 25 Fama-French size and book-to-market portfolios. The option-based results use premia estimated among the 10 option portfolios themselves. We report the betas (factor loadings) and pricing errors (alphas) for six of the 10 test portfolios (the results for the other four portfolios fall in between the reported ones). We run two-stage OLS with 10,000 bootstrap simulations. We report bootstrapped standard errors, root-mean-squared pricing errors, and a bootstrapped $p$-value for the joint hypothesis that all pricing errors are zero. Standard errors in parentheses.

as measured by the rms pricing errors. However, the conditional model featuring Volatility Jump with an equity-based premium leads to a negligible 3 bps pricing error for our most puzzling portfolio - the one made up of 30day OTM puts. The model does slightly worse on the other put portfolios, so the overall fit improves only marginally. Our interpretation is that shortdated OTM puts are particularly vulnerable to market conditions. Alternative conditioning variables are presented in the Online Appendix with largely negative results.

We conclude that three-factor unconditional models (in particular, the combination of Volatility Jump and Liquidity as factors along with the market) improve upon the two-factor models in explaining the cross-section of option returns. Conditional models do not improve upon unconditional ones overall, but conditioning on Liquidity in our model with Volatility Jump and an equity-based premium eliminates the pricing error on short-maturity OTM puts.

\section{Concluding Remarks}

We established that the leverage-adjusted returns on S\&P 500 Index options strongly reject the predictions of the Black-Scholes-Merton model. We then considered a wide range of unconditional factor pricing models, where the factor premia are estimated either from the universe of equities or the universe of options. Of all the factors that we considered, the four crisis-related factors, 
Table 9

Conditional asset pricing tests with selected factors, April 1986 to January 2012

Factor premia

\begin{tabular}{|c|c|c|c|c|c|c|c|c|c|c|}
\hline & & & & & & & & & & \\
\hline $1^{\text {st }}$ factor, intercept & So & $\notin P$ & $S \&$ & $P$ & & & $S c$ & $\&$ & $S \&$ & $\notin P$ \\
\hline Stock-based & 0.64 & $(0.30)$ & 0.47 & $(0.28)$ & 0.50 & $(0.30)$ & 0.53 & $(0.27)$ & 0.47 & $(0.29)$ \\
\hline Option-based & 0.60 & $(0.42)$ & 0.77 & $(0.37)$ & 0.44 & $(0.31)$ & 0.34 & $(0.31)$ & 0.60 & $(0.57)$ \\
\hline Difference & 0.03 & $(0.33)$ & 0.30 & $(0.30)$ & 0.06 & $(0.22)$ & 0.19 & $(0.22)$ & 0.12 & $(0.58)$ \\
\hline $1^{\text {st }}$ factor, slope & $S c$ & 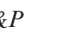 & $S \&$ & $\& P$ & & & $S c$ & $\varepsilon P$ & $S \&$ & $\& P$ \\
\hline Stock-based & 0.03 & $(0.12)$ & 0.27 & $(0.13)$ & 0.23 & $(0.15)$ & 0.01 & $(0.13)$ & 0.05 & $(0.15)$ \\
\hline Option-based & 1.25 & $(0.51)$ & 0.07 & $(0.13)$ & 0.09 & $(0.13)$ & 0.22 & $(0.11)$ & 0.16 & $(0.27)$ \\
\hline Difference & 1.22 & $(0.52)$ & 0.20 & $(0.18)$ & 0.13 & $(0.19)$ & 0.21 & $(0.17)$ & 0.21 & $(0.30)$ \\
\hline $2^{\text {nd }}$ factor, intercept & & & Juı & $m p$ & Volatil & Jump & Vola & tility & Liqu & idity \\
\hline Stock-based & & & 1.13 & $(0.85)$ & 2.72 & $(1.88)$ & 1.78 & $(0.86)$ & 6.01 & $(2.04)$ \\
\hline Option-based & & & 1.52 & (1.49) & 3.46 & (1.64) & 1.78 & $(0.52)$ & 14.15 & $(6.08)$ \\
\hline Difference & & & 0.40 & $(1.73)$ & 0.74 & $(2.45)$ & 0.00 & $(0.95)$ & 8.14 & $(6.26)$ \\
\hline $2^{\text {nd }}$ factor, slope & & & Jur & $m p$ & Volatil & Jump & Vola & tility & Liqu & idity \\
\hline Stock-based & & & 0.23 & $(0.15)$ & 0.62 & $(0.60)$ & 0.48 & $(0.24)$ & 0.20 & $(0.21)$ \\
\hline Option-based & & & 0.15 & $(0.32)$ & 0.00 & $(0.42)$ & 0.21 & $(0.14)$ & 0.65 & $(0.60)$ \\
\hline Difference & & & 0.39 & $(0.35)$ & 0.62 & $(0.67)$ & 0.69 & $(0.28)$ & 0.45 & $(0.63)$ \\
\hline & & & & Beta & $\begin{array}{c}\text { Call } \\
\text { ntercep }\end{array}$ & $\begin{array}{l}\text { tfolios } \\
\text { for } 2^{\text {nd }}\end{array}$ & ctor) & & & \\
\hline 30 days, $95 \%$ & 0.86 & $(0.00)$ & 0.30 & $(0.00)$ & 0.10 & $(0.00)$ & 0.14 & $(0.00)$ & 0.05 & $(0.00)$ \\
\hline 30 days, $105 \%$ & 0.72 & $(0.00)$ & 0.44 & $(0.00)$ & 0.19 & $(0.00)$ & 0.33 & $(0.00)$ & 0.08 & $(0.00)$ \\
\hline 90 days, $95 \%$ & 0.86 & $(0.00)$ & 0.31 & $(0.00)$ & 0.11 & $(0.00)$ & 0.15 & $(0.00)$ & 0.05 & $(0.00)$ \\
\hline 90 days, $105 \%$ & 0.81 & $(0.00)$ & 0.41 & $(0.00)$ & 0.17 & $(0.00)$ & 0.31 & $(0.00)$ & 0.06 & $(0.00)$ \\
\hline
\end{tabular}

Betas, slope (for $2^{\text {nd }}$ factor)

\begin{tabular}{lllllllllll}
\hline 30 days, $95 \%$ & 0.13 & $(0.00)$ & 1.29 & $(0.00)$ & 0.31 & $(0.00)$ & 0.14 & $(0.00)$ & 0.58 & $(0.00)$ \\
30 days, $105 \%$ & 0.24 & $(0.00)$ & 1.77 & $(0.00)$ & 0.53 & $(0.00)$ & 0.45 & $(0.00)$ & 0.75 & $(0.00)$ \\
90 days, $95 \%$ & 0.27 & $(0.00)$ & 1.29 & $(0.00)$ & 0.31 & $(0.00)$ & 0.17 & $(0.00)$ & 0.55 & $(0.00)$ \\
90 days, $105 \%$ & 0.60 & $(0.00)$ & 1.65 & $(0.00)$ & 0.42 & $(0.00)$ & 0.56 & $(0.00)$ & 0.72 & $(0.00)$ \\
\hline
\end{tabular}

Alphas (using stock-based premia)

\begin{tabular}{lllllllllll}
\hline 30 days, 95\% & 0.45 & $(0.16)$ & 0.41 & $(0.23)$ & 0.03 & $(0.25)$ & 0.23 & $(0.18)$ & 0.19 & $(0.24)$ \\
30 days, 105\% & 0.73 & $(0.20)$ & 0.74 & $(0.31)$ & 0.05 & $(0.38)$ & 0.41 & $(0.29)$ & 0.33 & $(0.31)$ \\
90 days, 95\% & 0.43 & $(0.16)$ & 0.42 & $(0.23)$ & 0.03 & $(0.25)$ & 0.21 & $(0.18)$ & 0.15 & $(0.24)$ \\
90 days, 105\% & 0.51 & $(0.20)$ & 0.61 & $(0.31)$ & 0.10 & $(0.34)$ & 0.27 & $(0.29)$ & 0.23 & $(0.29)$ \\
\hline
\end{tabular}

Alphas (using option-based premia)

\begin{tabular}{lcccccccccc}
\hline 30 days, $95 \%$ & 0.26 & $(0.12)$ & 0.00 & $(0.04)$ & 0.01 & $(0.04)$ & 0.01 & $(0.03)$ & 0.09 & $(0.08)$ \\
30 days, $105 \%$ & 0.41 & $(0.20)$ & 0.03 & $(0.07)$ & 0.03 & $(0.06)$ & 0.02 & $(0.07)$ & 0.04 & $(0.13)$ \\
90 days, $95 \%$ & 0.07 & $(0.11)$ & 0.01 & $(0.04)$ & 0.03 & $(0.04)$ & 0.01 & $(0.03)$ & 0.01 & $(0.07)$ \\
90 days, $105 \%$ & 0.25 & $(0.23)$ & 0.09 & $(0.04)$ & 0.11 & $(0.04)$ & 0.13 & $(0.03)$ & 0.06 & $(0.10)$ \\
\hline
\end{tabular}

Put portfolios

Betas, intercept (for $2^{\text {nd }}$ factor)

\begin{tabular}{lcccccccccc}
\hline 30 days, $95 \%$ & 1.03 & $(0.00)$ & 0.21 & $(0.00)$ & 0.20 & $(0.00)$ & 0.47 & $(0.00)$ & 0.02 & $(0.00)$ \\
30 days, 105\% & 0.97 & $(0.00)$ & 0.10 & $(0.00)$ & 0.04 & $(0.00)$ & 0.11 & $(0.00)$ & 0.03 & $(0.00)$ \\
90 days, 95\% & 1.04 & $(0.00)$ & 0.13 & $(0.00)$ & 0.15 & $(0.00)$ & 0.36 & $(0.00)$ & 0.01 & $(0.00)$ \\
90 days, $105 \%$ & 0.97 & $(0.00)$ & 0.07 & $(0.00)$ & 0.05 & $(0.00)$ & 0.15 & $(0.00)$ & 0.03 & $(0.00)$ \\
\hline
\end{tabular}


Table 9

Continued

Factor premia

\begin{tabular}{|c|c|c|c|c|c|c|c|c|c|c|}
\hline \multirow[t]{2}{*}{$1^{\text {st }}$ factor, intercept } & \multicolumn{2}{|c|}{$S \& P$} & \multicolumn{2}{|c|}{$S \& P$} & \multicolumn{2}{|c|}{$S \& P$} & \multicolumn{2}{|c|}{$S \& P$} & \multicolumn{2}{|c|}{$S \& P$} \\
\hline & \multicolumn{10}{|c|}{ Betas, slope (for $2^{\text {nd }}$ factor) } \\
\hline 30 days, $95 \%$ & 0.11 & $(0.00)$ & 0.15 & $(0.00)$ & 0.66 & $(0.00)$ & 0.56 & $(0.00)$ & 0.41 & $(0.00)$ \\
\hline 30 days, $105 \%$ & 0.26 & $(0.00)$ & 1.19 & $(0.00)$ & 0.17 & $(0.00)$ & 0.06 & $(0.00)$ & 0.36 & $(0.00)$ \\
\hline 90 days, $95 \%$ & 0.03 & $(0.00)$ & 0.38 & $(0.00)$ & 0.53 & $(0.00)$ & 0.29 & $(0.00)$ & 0.37 & $(0.00)$ \\
\hline 90 days, $105 \%$ & 0.08 & $(0.00)$ & 1.02 & $(0.00)$ & 0.17 & $(0.00)$ & 0.12 & $(0.00)$ & 0.39 & $(0.00)$ \\
\hline
\end{tabular}

Alphas (using stock-based premia)

\begin{tabular}{lccccccccccc}
\hline 30 days, 95\% & 0.67 & $(0.24)$ & 0.53 & $(0.38)$ & 0.03 & $(0.46)$ & 0.38 & $(0.43)$ & 0.61 & $(0.35)$ \\
30 days, 105\% & 0.14 & $(0.17)$ & 0.36 & $(0.23)$ & 0.24 & $(0.25)$ & 0.23 & $(0.21)$ & 0.08 & $(0.26)$ \\
90 days, 95\% & 0.10 & $(0.20)$ & 0.03 & $(0.31)$ & 0.35 & $(0.36)$ & 0.16 & $(0.34)$ & 0.13 & $(0.30)$ \\
90 days, 105\% & 0.14 & $(0.17)$ & 0.24 & $(0.23)$ & 0.21 & $(0.25)$ & 0.20 & $(0.22)$ & 0.09 & $(0.26)$ \\
\hline \multicolumn{10}{c}{ Alphas (using option-based premia) } \\
\hline 30 days, 95\% & 0.57 & $(0.17)$ & 0.25 & $(0.09)$ & 0.27 & $(0.06)$ & 0.24 & $(0.06)$ & 0.15 & $(0.14)$ \\
30 days, $105 \%$ & 0.21 & $(0.14)$ & 0.02 & $(0.04)$ & 0.10 & $(0.04)$ & 0.04 & $(0.03)$ & 0.11 & $(0.09)$ \\
90 days, $95 \%$ & 0.10 & $(0.15)$ & 0.17 & $(0.06)$ & 0.14 & $(0.04)$ & 0.13 & $(0.04)$ & 0.19 & $(0.09)$ \\
90 days, $105 \%$ & 0.20 & $(0.10)$ & 0.05 & $(0.05)$ & 0.11 & $(0.04)$ & 0.07 & $(0.03)$ & 0.04 & $(0.09)$ \\
\hline
\end{tabular}

Stock portfolio test statistics (using stock-based premia)

\begin{tabular}{lllllllllll}
\hline R.m.s. (p) & 0.26 & $(0.00)$ & 0.21 & $(0.07)$ & 0.20 & $(0.03)$ & 0.24 & $(0.00)$ & 0.21 & $(0.02)$
\end{tabular}

Option portfolio test statistics (using stock-based premia)

\begin{tabular}{lllllllllll}
\hline R.m.s. (p) & 0.47 & $(0.02)$ & 0.48 & $(0.41)$ & 0.18 & $(0.52)$ & 0.27 & $(0.40)$ & 0.30 & $(0.09)$ \\
\hline
\end{tabular}

Option portfolio test statistics (using option-based premia)

\begin{tabular}{lllllllllll}
\hline R.m.s. (p) & 0.31 & $(0.48)$ & 0.12 & $(0.42)$ & 0.13 & $(0.23)$ & 0.13 & $(0.18)$ & 0.13 & $(0.66)$
\end{tabular}

The conditioning variable is the level of Liquidity. The stock-based (option-based) results estimate factor premia from the 25 Fama-French portfolios (54 option portfolios). We report betas (factor loadings) and pricing errors (alphas) for four representative portfolios (the rest fall in between). We run two-stage OLS with 10,000 bootstrap simulations. We report bootstrapped standard errors, root-mean-squared pricing errors, and a bootstrapped $p$-value for the joint hypothesis that all pricing errors are zero. Standard errors in parentheses.

Jump, Volatility Jump, Volatility, and Liquidity, are the only ones that work reasonably well in explaining the cross-section of index option returns. Furthermore, in a model with Volatility Jump using Liquidity as a conditioning variable and an equity-based premium, the pricing error on short-dated OTM puts disappears.

An important methodological contribution of the paper is the construction (and public availability) of a panel of de-levered monthly returns of option portfolios split across type, maturity, and moneyness. This construction lowers the skewness of the monthly portfolio returns and renders them close to normal thereby allowing the future exploration of alternative linear factor models, as well as linear forecasting models. 


\section{Appendix A: Data Sets}

The master Berkeley Option Database consists of intraday quotes on individual options. We seek to extract a single end-of-day cross-section of quotes, comparable to the quotes provided by OptionMetrics in the latter part of our sample. In addition, we seek to avoid the issue of non-synchronous trading. To that end, on each trading day, we find the minute between 3:00 PM and 4:00 PM Central Standard Time with the largest number of simultaneous quotes. We stop at 4:00 PM because the market closes at 4:15 PM and we wish to avoid contamination relating to last minute trading activity. We record all option quotes in that minute.

Next we add not so far recorded quotes in the adjacent minutes within the same hour one after the other. Here we assume that the implied volatilities stay constant within that final hour of the day. Based on this assumption, we create hypothetical option prices for the option in adjacent minutes. About half of our observations from the Berkeley database are obtained from a single minute. The pattern of returns across our portfolios remains unchanged if we use only the observations obtained from the single minute.

We also record the intraday volume of each of our end-of-day options, as well as total daily call volume and total daily put volume. We further collect the present value of all realized dividend payments during the remaining life of each option, discounting with the relevant constant maturity T-bill rate from the H.15 statistical release of the Federal Reserve. We work out the associated continuously compounded dividend yield.

\section{Appendix B: Filters}

We apply three levels of filters designed to minimize possible quoting errors. In constructing our portfolios, we apply these filters on the trade-in (buy) side to make sure that we are buying into reliable quotes. Applying our filters on the buy side minimizes the problem of having to make up trade-out prices for options that were bought but cannot be sold due to missing observations. When we seek to exit our position, if no quote is available in the filtered data, we look for a price in the raw data. The filters are described below.

\section{Level 1 filters}

"Identical" Filter: The OptionMetrics data set contain duplicate observations, defined as two or more quotes with identical option type, strike, expiration date, and price. In each such case, we eliminate all but one of the quotes.

"Identical Except Price" Filter: There are a few sets of quotes with identical terms (type, strike, and maturity) but different prices. When this occurs, we keep the quote whose T-bill-based implied volatility is closest to that of its moneyness neighbors, and delete the others. 
"Bid = 0" Filter: We remove quotes of zero for bids, thereby avoiding lowvalued options. Also, a zero bid may indicate censoring as negative bids cannot be recorded.

\section{Level 2 filters}

"Days to Maturity $<\mathbf{7}$ or $>\mathbf{1 8 0 "}$ " Filter: We remove all options with fewer than seven or more than 180 calendar days to expiration. The short maturity options tend to move erratically close to expiration and the long maturity options lack volume and open interest.

"IV $<\mathbf{5 \%}$ or $>\mathbf{1 0 0 \% " ~ F i l t e r : ~ W e ~ r e m o v e ~ a l l ~ o p t i o n ~ q u o t e s ~ w i t h ~ i m p l i e d ~ v o l a - ~}$ tilities lower than $5 \%$ or higher than $100 \%$, computed using T-bill interest rates. Such extreme values likely indicate quotation problems or simply low value.

"Moneyness $<\mathbf{0 . 8}$ or $>\mathbf{1 . 2}$ " Filter: We remove all option quotes with moneyness, the ratio of strike price to index price, below 0.8 or above 1.2. These options have little value beyond their intrinsic value and are also very thinly traded.

"Implied Interest Rate $<$ 0" Filter: When filtering outliers, we use T-bill interest rates to compute implied volatilities. T-bill interest rates are obtained from the Federal Reserve's H.15 release. We assign a T-bill rate to each observation by assuming that we can use the next shortest rate if the time to expiration of the option is shorter than the shortest constant maturity rate.

Our goal is to obtain an interest rate that is as close as possible to the one faced by investors in the options market. It appears that the T-bill rates are not the relevant ones when pricing these options. Specifically, when the T-bill rates are used, put and call implied volatilities do not line up very well; for example, the T-bill rate tends to be too high for short maturity options, perhaps because no T-bill has maturity of less than a month. To address these issues, we compute a put-call parity-implied interest rate. Since we believe that put-call parity holds reasonably well in this deep and liquid European options market, we use the put-call parity-implied interest rate as our interest rate in the remainder of the paper and for further filters.

To construct this rate, we take all put-call pairs of a given maturity and impose put-call parity using the bid-ask midpoint as the price, and allowing the interest rate to adjust. We remove 89,563 pairs with a negative implied interest rate. We then take the median-implied interest rate across all remaining pairs of the same maturity with moneyness between 0.95 and 1.05 and assign it to all quotes with that maturity. We are able to directly assign an implied interest rate to $93 \%$ of our sample in this way. We fill in the gaps by interpolating across maturities and if necessary, across days. Our implied interest rate is on average 54 bps above the T-bill rate. 
"Unable to Compute IV" Filter: We remove quotes that imply negative time value.

\section{Level 3 Filters}

"IV" Filter: We remove implied volatility outliers to reduce the prevalence of apparent butterfly arbitrage. For each date and maturity, we fit a quadratic curve (separately to puts and calls) through the observed log implied volatilities. We calibrate a confidence band around all curves using the entire sample. Combining the information from all days and maturities in the sample, we compute a typical (one standard deviation) relative distance in percent from the level of the fitted curve for different levels of moneyness $(0.8,0.85, \ldots, 1.2)$. Thus, for each fitted IV curve, we compute the relative distance of all option IVs from the fitted IV curve and we calculate the standard deviation of these relative distances for each moneyness bin. In a second pass, we check for each option's IV, how many standard deviations it is apart from the fitted IV curve. These distances are tight in and around the money (about 2\%) and wide in the out of the money range (around 3.5\%).

"Put-call Parity" Filter: For every put-call pair with the same date, maturity, and moneyness, we insure that put-call parity holds and that violations are eliminated. Thus, for each put-call pair, we find the bid-ask midpoint put-call parity-implied interest rate. Next, we trim outliers in a similar way as with the IV filter. Specifically, we use the whole sample of distances of the put-callparity-implied interest rates from the corresponding daily median-implied interest rate to find the standard deviation of the corresponding distances. This distance is computed to be about 90 bps.

We record the number of observations at each filtering level in Table B.1. Before the application of the filters, the Berkeley database consists of 269,460 observations and the OptionMetrics database consists of 3,410,396 observations. Level 1 filters eliminate $8 \%$ of the prices from the OptionMetrics database but none from the Berkeley database. Level 2 filters eliminate about $28 \%$ of the observations from Berkeley and as many as 66\% from OptionMetrics (mostly the maturity filter) and level 3 filters eliminate $10 \%$ of observations from each dataset. We also note that our filters produce 124 trading days with no surviving observations. These dropped days represent less than $2 \%$ of the trading days in our sample and since they are determined without the use of forward-looking information, we safely do not rebalance our portfolios during those days.

Next, we compute implied volatilities based on the put-call parity-implied interest rate, and $95 \%$ of these are within $1.4 \%$ of the T-bill-implied volatilities. In the remainder of the paper, we work exclusively with these implied volatilities. 


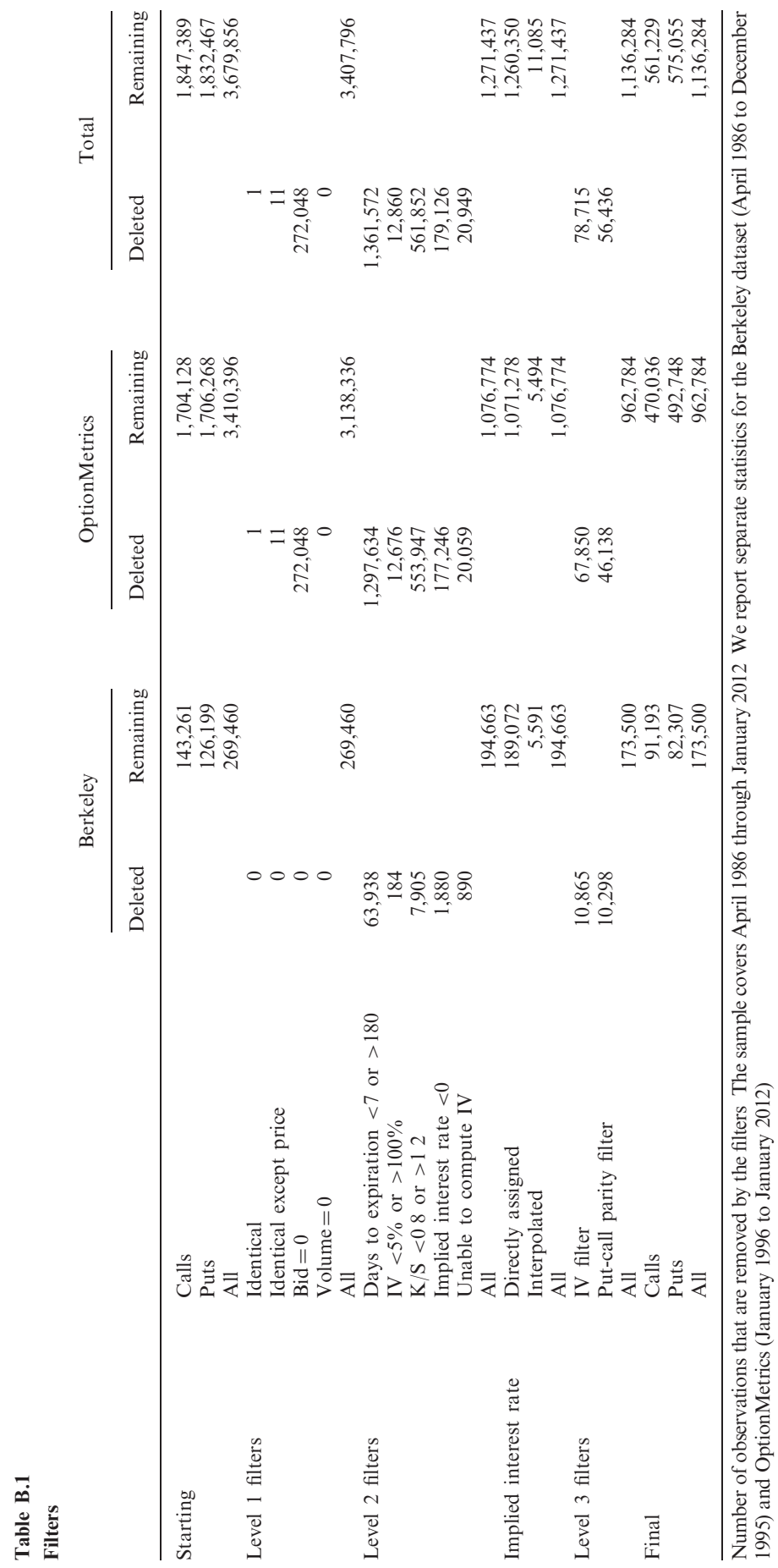




\section{References}

Barro, R. J. 2006. Rare disasters and asset markets in the 20th century. Quarterly Journal of Economics 121: 82366.

Bates, D. S. 1996. Jumps and stochastic volatility: Exchange rate processes implicit in deutsche mark options. Review of Financial Studies 9:69 107.

. 2008. The market for crash risk. Journal of Economic Dynamics and Control 32:2291 321.

Black, F., and M. Scholes. 1973. The pricing of options and corporate liabilities. Journal of Political Economy 81: 63754

Bollen, N. P., and R. E. Whaley. 2004. Does net buying pressure affect the shape of implied volatility functions? Journal of Finance 59:711 53 .

Brennan, M. J., X. Liu, and Y. Xia. 2008. Option pricing kernels and the ICAPM. Working paper, UCLA.

Broadie, M., M. Chernov, and M. Johannes. 2009. Understanding index option returns. Review of Financial Studies 22:4493 529 .

Buraschi, A., and J. C. Jackwerth. 2001. The price of a smile: Hedging and spanning in option markets. Review of Financial Studies 14:495 527.

Buraschi, A., F. Trojani, and A. Vedolin. 2011. When uncertainty blows in the orchard: Comovement and equilibrium volatility risk premia. Working paper, Imperial College, London.

Cao, C., and J. Huang. 2008. Determinants of S\&P 500 index option returns. Review of Derivatives Research 10: 138.

Carverhill, A. P., T. H. F. Cheuk, and S. Dyrting. 2009. The smirk in the S\&P500 futures options prices: A linearized factor analysis. Working paper, University of Hong Kong.

Christoffersen, P., R. Goyenko, K. Jacobs, and M. Karoui. 2011. Illiquidity premia in the equity options market. Working paper, McGill University.

Christoffersen, P., S. Heston, and K. Jacobs. 2006. Option valuation with conditional skewness. Journal of Econometrics 131:253 84

Constantinides, G. M., M. Czerwonko, J. C. Jackwerth, and S. Perrakis. 2011. Are options on index futures profitable for risk averse investors? Empirical evidence. Journal of Finance 66:1407 37.

Constantinides, G. M., J. C. Jackwerth, and S. Perrakis. 2009. Mispricing of S\&P 500 index options. Review of Financial Studies 22:1247 77.

Coval, J. D., and T. Shumway. 2001. Expected option returns. Journal of Finance 56:983 1009.

Drechsler, I., and A. Yaron. 2011. What's vol got to do with it. Review of Financial Studies 24:1 45.

Duarte, J., and C. S. Jones. 2007. The price of market volatility risk. Working paper, Rice University.

Eraker, B., M. S. Johannes, and N. Polson. 2003. The impact of jumps in volatility and returns. Journal of Finance 58:1269 1300.

Frazzini, A., and L. H. Petersen. 2011. Embedded leverage. Working paper, New York University.

Hull, J. C. 2012. Options, futures, and other derivatives, 8th ed. New York, NY: Prentice Hall.

Jackwerth, J. C. 2004. Option-implied risk-neutral distributions and risk aversion. Charlottesville, VA: Research Foundation of AIMR.

Jones, C. S. 2006. A nonlinear factor analysis of S\&P 500 index options returns. Journal of Finance 61:2325 63.

Lewellen, J., S. Nagel, and J. Shanken. 2010. A skeptical appraisal of asset pricing tests. Journal of Financial Economics 96:175 94 . 
Lian, L. 2011. Do price and volatility jumps explain the cross-section of option prices? Working paper, University of Massachusetts.

McDonald, R. L. 2013. Derivatives markets, 3rd ed. Boston, MA: Prentice Hall.

Merton, R. C. 1973. Theory of rational option pricing. Bell Journal of Economics and Management Science 4: 14183.

Pastor, L., and R. F. Stambaugh. 2003. Liquidity risk and expected stock returns. Journal of Political Economy 111:642 85.

Rietz, T. A. 1988. The equity risk premium: a solution. Journal of Monetary Economics 22:117 31.

SSerban, M., J. Lehoczky, and D. Seppi. 2008. Cross-sectional stock option pricing and factor models of returns. Working paper, Carnegie-Mellon University.

Singleton, K. J. 2006. Empirical dynamic asset pricing, 1st ed. Boston, MA: Prentice Hall. 